\title{
ON THE MANIPULABILITY OF COMPETITIVE EQUILIBRIUM RULES IN MANY-TO-MANY BUYER-SELLER MARKETS ${ }^{1}$
}

\section{By}

\section{David Pérez-Castrillo $^{2}$ and Marilda Sotomayor ${ }^{3}$}

\begin{abstract}
We analyze the manipulability of competitive equilibrium allocation rules for the simplest many-to-many extension of Shapley and Shubik's (1972) assignment game. First, we show that if an agent has a quota of one, then she does not have an incentive to manipulate any competitive equilibrium rule that gives her her most preferred competitive equilibrium payoff when she reports truthfully. In particular, this result extends to the one-to-many (respectively, many-to-one) models the Non-Manipulability Theorem of the buyers (respectively, sellers), proven by Demange (1982), Leonard (1983), and Demange and Gale (1985) for the assignment game. Second, we prove a "General Manipulability Theorem" that implies and generalizes two "folk theorems" for the assignment game, the Manipulability Theorem and the General Impossibility Theorem, never proven before. For the one-to-one case, this result provides a sort of converse of the Non-Manipulability Theorem.
\end{abstract}

Keywords: matching, competitive equilibrium, optimal competitive equilibrium, manipulability, competitive equilibrium rule.

JEL: C78, D78

\footnotetext{
${ }^{1}$ We thank participants of seminars at the Universities of Salamanca, Valencia, Osaka, Waseda, East Anglia, and Seoul National, at the workshop on Game Theory in Rio de Janeiro, MOVE-Jerusalem, and ASSET meeting in Aix Marseille, as well as two reviewers and an Associate Editor for very helpful comments for very helpful comments. Marilda Sotomayor acknowledges financial support from CNPqBrazil. David Pérez-Castrillo is a fellow of MOVE. He acknowledges financial support from the Ministerio de Ciencia y Tecnología (ECO2012-31962 and ECO2015-63679-P), Generalitat de Catalunya (2014SGR-142), the Severo Ochoa Programme for Centres of Excellence in R\&D (SEV-2015-0563) and ICREA Academia. Previous versions of this paper, analyzing one-to-one matching models only, circulated under the titles "Two Folk Manipulability Theorems in One-to-one Two-sided Matching Markets with Money as a Continuous Variable" and "Two Folk Manipulability Theorems in the General One-to-one Two-sided Matching Markets with Money."

${ }^{2}$ Universitat Autònoma de Barcelona and Barcelona GSE; Dept. Economía e Hist. Económica; Edificio B; 08193 Bellaterra - Barcelona; Spain. Email: david.perez@uab.es

3 Universidade de São Paulo-SP; Dep de Economia; Av. Prof. Luciano Gualberto, 908; Cidade Universitária, 5508-900, São Paulo, SP; and Graduate School of Economics, Getulio Vargas FoundationRJ; Praia de Botafogo,190, 22250-900, Rio de Janeiro, RJ, Brazil. Email: marildas@usp.br
} 


\section{INTRODUCTION}

We study two-sided matching markets where a finite number of sellers (or workers) meet a finite number of buyers (or firms). Each seller owns and is willing to sell a set of objects, and each buyer wants to buy several objects, up to her quota, from various sellers. Both types of agents derive utility from money and objects, and their utility functions are additively separable. The objects sold by each particular seller are identical, but sellers are heterogeneous, in the sense that the sellers' object types are different from a buyer's point of view. Buyers are also heterogeneous in terms of preferences because a buyer's willingness to pay for an object may be different from that of another buyer.

The many-to-many two-sided matching model that we analyze was proposed and studied in Sotomayor (1992), (1999), (2007) and it was called the multiple-partners assignment game. It is the simplest generalization of the assignment game (Shapley and Shubik 1972), a model where each seller owns and is willing to sell only one object, and each buyer wants to buy one object at most. ${ }^{4}$

We call our market the buyer-seller market. Roughly speaking, a competitive equilibrium in a buyer-seller market is a vector of prices, one for each object, and an allocation of objects to buyers such that the demand of every buyer is satisfied, the number of a seller's objects allocated is not larger than his supply and the prices of unsold objects are their valuation for the sellers. The set of equilibrium prices is nonempty and is a complete lattice whose extreme points are the minimum and the maximum equilibrium prices, which are called buyer-optimal and seller-optimal equilibrium prices, respectively. ${ }^{5,6}$

Given a set of buyers and sellers with their respective quotas, a competitive equilibrium rule is a function that selects a unique competitive equilibrium allocation for every market. When a competitive equilibrium rule is adopted, information about the valuation of the agents is required. Therefore, the rule induces a strategic game. In this

\footnotetext{
${ }^{4}$ Crawford and Knoer (1981) studied the linear model where the utility of the seller depends on the identity of the buyer. Kelso and Crawford (1982) extended the analysis to many-to-one matching models.

5 The competitive one-to-one market was proposed in Gale (1960), who proved the existence of equilibrium prices in this market. Shapley and Shubik (1972) showed that the set of equilibrium prices form a complete lattice whose extreme points are the minimum and the maximum equilibrium prices. Sotomayor (2007) introduced the concept of a competitive equilibrium payoff for the multiple-partners assignment game and extended the previous results for this environment. She also proved that the set of competitive equilibrium payoffs is a subset of the set of stable payoffs and may be smaller than this set.

${ }^{6}$ Our results are established for the competitive market game. For the assignment game, they can easily be transferred to the cooperative model because the core coincides with the set of competitive equilibrium payoffs (Shapley and Shubik 1972).
} 
paper, we study the agents' incentives to report truthfully when a competitive equilibrium rule is used.

The first important result in the literature concerning agents' incentives is the NonManipulability Theorem for the assignment game, proposed by Demange (1982) and Leonard (1983). These authors proved that if the buyer-optimal (or seller-optimal) competitive equilibrium rule is used, then no buyer (or seller) can profit by misstating her (or his) true valuations. ${ }^{7}$

The room for manipulation is large for agents who can buy or sell several objects and we show that the Non-Manipulability Theorem does not extend to the (many-tomany) buyer-seller markets. However, we prove that an agent with a quota of one never has an incentive to manipulate any competitive equilibrium rule that yields her/his most preferred competitive equilibrium payoff when s/he reports truthfully. Moreover, we show that the buyer-optimal (respectively, seller-optimal) competitive equilibrium rule for a one-to-many (respectively, many-to-one) buyer-seller market is not only individual strategy-proof but also group strategy-proof for the buyers (respectively, sellers).

The second important result in the literature is the Impossibility Theorem (Roth and Sotomayor, 1990). It provides an assignment game with one seller and $n>1$ buyers where, under any competitive equilibrium rule, there is an agent who has an incentive to misrepresent her/his valuation. Demange and Gale (1985) presented several examples of assignment markets where a competitive equilibrium rule that yields the optimal competitive equilibrium for one side of the market provides incentives to an agent belonging to the other side to misrepresent her/his valuation. The main feature of all the examples is that the markets have more than one vector of equilibrium prices.

It was believed that the phenomena observed in the previous examples can extend to any assignment market with more than one vector of equilibrium prices. Along the years, this belief has supported two "folk theorems" for the assignment game, which have never been proven in the literature. For the more general buyer-seller markets that we analyze, the two theorems can be expressed as follows. The Manipulability Theorem states that if the buyer-optimal (respectively, seller-optimal) competitive equilibrium rule is used in a market with more than one vector of equilibrium prices, then there is a

\footnotetext{
7 Demange and Gale (1985) extended the Non-Manipulability Theorem to a one-to-one buyer-seller model where the utilities are continuous in money, but are not necessarily linear. They also extended it to any competitive equilibrium rule that maps the market defined by the true valuations to the buyer-optimal (or seller-optimal) competitive equilibrium for this market. Under the assumption that there are no monetary transfers between buyers (respectively, sellers), these authors proved that such a rule is collectively non-manipulable by the buyers (respectively, sellers).
} 
seller (respectively, buyer) who can profitably misrepresent his (respectively, her) valuations. The General Impossibility Theorem asserts that if a market has more than one vector of equilibrium prices, then every competitive equilibrium rule can be manipulated by some agent.

We provide the proofs and formal statements of the two theorems, extended to the many-to-many buyer-seller market, aiming to fill this gap in the literature. Indeed, we give a simple proof of a stronger and more General Manipulability Theorem: Any agent who does not receive her/his optimal competitive equilibrium payoff under a competitive rule can profitably misrepresent her/his valuations, assuming the others tell the truth.

Our theorems allow the following necessary and sufficient condition to be stated: an agent with a quota of one cannot manipulate a rule in a market if and only if the rule gives to her/him her/his most preferred equilibrium payoff. In particular, for the assignment game, if a competitive equilibrium rule is strategy-proof for the buyers (respectively, sellers), then the rule maps the profile of true valuations to the buyeroptimal (respectively, seller-optimal) competitive equilibrium price. This result is mathematically unusual because it provides a way of concluding that a competitive equilibrium rule is, for example, strategy-proof for the buyers, based only on the direct examination of the agents' payoffs obtained by the profile of true valuations.

Miyake (1998) considers the buyer-optimal mechanism in the assignment game as a multi-item generalization of Vickrey's second price auction. In a framework where the sellers' valuations are fixed and known, he shows that the honest strategy profile is not a Nash equilibrium for the buyers, for any competitive equilibrium rule other than the buyer-optimal one. We strengthen Miyake's (1998) result because we also take into account the sellers' incentives and extend the result to many-to-many markets. Also, we provide a simpler proof. In a general one-to-many buyer-seller model with (a finite set of) contracts, Hatfield and Milgrom (2005) show that the buyer-optimal competitive equilibrium is strategy-proof for the buyers and Sakai (2011) shows that it is the unique equilibrium rule that is strategy-proof for the buyers.

Demange and Gale (1985) consider the strategic equilibrium of the game induced by the buyer-optimal competitive equilibrium rule if the buyers play their sincere strategies and the sellers can only manipulate their valuations. Sotomayor (2000) analyzes the case in which the rule produces a competitive equilibrium payoff and there is no restriction on the strategies selected by the agents. Related results are proven for 
the marriage market in Roth and Sotomayor (1990). Sotomayor (2012) proves a manipulability theorem and an impossibility theorem for the college admission market. ${ }^{8}$

Several authors have studied the manipulability of envy-free allocation rules in fair allocation models, where a finite number of bundles are assigned to a finite number of agents. Although the notions of equilibrium in the assignment game and envy-free in the fair allocation models are different (in particular, there are no sellers in the second model), the agents' incentives to manipulate are similar to those of the buyers in the assignment game. Sun and Yang (2003), Andersson and Svensson (2008), and Svensson (2009) characterize the set of envy-free and coalitionally strategy-proof allocation rules when a bundle of objects and a limited budget have to be distributed among agents. Any such rule fixes a maximal compensation for each object, and as a function of the preferences reported by the agents, a "maximal" (in the sense that it distributes the largest amount of money) envy-free allocation is chosen respecting the fixed compensations for any object. Andersson, Ehlers, and Svensson (2014) and Fujinaka and Wakayama (2015) have independently found some properties concerning the manipulation of envy-free allocation rules in the one-to-one fair allocation model that have a similar flavor as the properties that we provide for equilibrium rules in the manyto-many matching problem. In particular, they show a result in the same spirit as our General Manipulability Theorem: any individual can manipulate an envy-free allocation rule if it does not guarantee him the best outcome in the set of envy-free allocations.

Finally, the concern about buyers' manipulation of their true willingness to pay is also present in the auction literature. In the English auction, which leads to the minimum equilibrium prices, buyers do not have an incentive to misrepresent their preferences when they all have a unit demand (Leonard 1983; Demange, Gale, and Sotomayor 1986), or all the units auctioned are homogeneous and buyers have decreasing marginal utilities (Ausubel 2004). On the other hand, Gul and Stacchetti (2000), building on the work of Kelso and Crawford (1982), provide a generalization of the English auction to situations where each buyer may wish to acquire several heterogeneous objects (and their preferences satisfy the gross substitutes condition). They show that a truthful revelation of preferences cannot be guaranteed in general. ${ }^{9}$

\footnotetext{
${ }^{8}$ For some analyses of the consequences of manipulation in the marriage and the college admission models, see Roth (1985), Kojima and Pathak (2009), Ma (2010), and Jaramillo, Kayi, and Klijn (2013).

${ }^{9}$ Se also some more recent papers on dynamic auctions for multiple heterogeneous items (Ausubel 2006; Sun and Yang 2014). They consider bidders who can demand multiple heterogeneous items and have a general utility function over bundles (not necessarily separable or additive). They develop dynamic
} 


\section{2-THE FRAMEWORK AND PRELIMINARIES}

A market $M$ involves two finite and disjoint sets of agents, $B$ and $S$, which can be thought of as being buyers and sellers, respectively. Set $B$ has $m$ buyers and set $S$ has $n$ sellers. Each seller $s_{k}$ owns $t\left(s_{k}\right)$ identical objects, and we also denote $s_{k}$ the type of the objects owned by that seller. Each buyer $b_{j}$ has a quota $t\left(b_{j}\right)$, representing the maximum number of objects she is allowed to acquire. No buyer is interested in acquiring more than one item from a given seller. We denote by $t_{B}$ and $t_{S}$ the array of numbers $t\left(b_{j}\right)$ 's and $t\left(s_{k}\right)$ 's, respectively. ${ }^{10}$

The value of an object $s_{k}$ is $r_{k} \geq 0$ for seller $s_{k}$ and $a_{j k} \geq 0$ for buyer $b_{j}$. The value $a_{j k}$ does not depend on the other objects that buyer $b_{j}$ acquires or on the other buyers acquiring objects of type $s_{k}$. Thus, if buyer $b_{j}$ purchases an object $s_{k}$ at price $p_{k} \geq r_{k}$, then her individual payoff in this transaction is $u_{j k}=a_{j k}-p_{k}$ and that of seller $s_{k}$ is $v_{j k}=p_{k}-r_{k}$. We denote by $a_{j}$ the vector of the values of $a_{j k}$ 's; the valuation matrix of the buyers and the valuation vector of the sellers are denoted by $a$ and $r$, respectively. A trade is acceptable to seller $s_{k}$ and buyer $b_{j}$ if the potential gain from the trade between the two agents is non-negative, that is, $a_{j k}-r_{k} \geq 0$.

For notational simplicity, the set $B$ includes a dummy buyer $b_{0}$ and the set $S$ includes a dummy seller $s_{0}$ who owns "dummy objects" $s_{0}$ whose valuation and price is zero, that is, $r_{0}=p_{0}=0$. The valuations of the dummy object are $a_{j 0}=0$ and the dummy buyer's valuations are $a_{0 k}=r_{k}$ for all $b_{j} \in B$ and $s_{k} \in S$. The quotas of the dummy agents are enough to guaranty that the real agents in the market can buy from, or sell to them as many objects as they need.

A feasible matching assigns each object to one buyer (possibly the dummy buyer) so that each non-dummy buyer $b_{j}$ is assigned to an admissible set of objects for her, that is, a set with $t\left(b_{j}\right)$ objects that contains at most one object of the same seller (although it may include several dummy objects). If a seller's object is assigned to a

auctions that are efficient and strategy-proof in the sense that sincere bidding by every bidder is an ex post perfect Nash equilibrium in the game.

${ }^{10}$ The situation where there is no restriction on the number of objects a buyer can acquire is a particular case of our model, by making the quota of every buyer equal to the total number of objects. However, the quota makes sense in many situations. Consider, for example, a market with three sellers, $s_{1}, s_{2}$ and $s_{3}$. Seller $s_{k}$ owns a number of cars of type $k$, for $k=1,2,3$. Suppose that buyer $b_{j}$ has in hand an offer from a client who will purchase two cars, at most, of different types at the price of $a_{j k}$ for $k=1,2,3$, should he obtain them in the market. Since buyer $b_{j}$ knows that he can earn $a_{j k}$ by reselling the car of type $k$, he will not buy at a higher price. And his quota is obviously 2 . 
buyer, we say that both agents are matched. If an object is allocated to the dummy buyer, we say that it is left unsold. Formally, ${ }^{11}$

Definition 2.1. A matching for $M$ is identified with a matrix $x=\left(x_{j k}\right)$ of non-negative numbers, defined for all pairs $\left(b_{j}, s_{k}\right) \in B \times S$ such that $x_{j k} \in\{0,1\}$ if $b_{j} \in B-b_{0}$ and $s_{k} \in S-s_{0}$. Under this identification, $x_{j k}>0$ if and only if $b_{j}$ and $s_{k}$ are matched to each other. A matching $x$ for $M$ is feasible if it satisfies (i) $\sum_{B} x_{j k}=t\left(s_{k}\right)$ for all $s_{k} \in S-s_{0}$, (ii) $\sum_{S} x_{j k}=t\left(b_{j}\right)$ for all $b_{j} \in B-b_{0}$ and (iii) $a_{j k}-r_{k} \geq 0$ if $x_{j k}=1$.

Given a feasible matching $x$, we denote by $C\left(b_{j}, x\right)$ the set of objects allocated to $b_{j}$ at $x$ and by $C\left(s_{k}, x\right)$ the set of buyers assigned to $s_{k}$ at $x$. Also, we denote $\underline{a}(a, r)_{j k}$ $\equiv a_{j k}-r_{k}$ if $a_{j k}-r_{k} \geq 0$ and $\underline{a}(a, r)_{j k} \equiv 0$ otherwise.

A feasible matching that maximizes total returns, in the sense that it generates the maximum surplus in the market $M$, is called an optimal matching.

Definition 2.2. A matching $x$ for $M$ is optimal if (i) it is feasible and (ii) $\sum_{B x S} \underline{a}(a, r)_{j k} x_{j k} \geq \sum_{B x S} \underline{a}(a, r)_{j k} x_{j k}^{\prime}$ for all feasible matchings $x^{\prime}$.

A feasible price vector $p$ for market $M$ is a function of $S$ to $R$ (the set of real numbers) that associates a price $p_{k} \geq r_{k}$ to each $s_{k} \in S$ (with $p_{0}=r_{0}=0$ ). A feasible allocation for $M$ is a pair $(p, x)$, where $p$ is a feasible price vector and $x$ is a feasible matching.

The value of an admissible set of objects $S^{\prime}$ to buyer $b_{j}$ is the sum of the values of the objects in $S^{\prime}$ to her, and similarly for any seller $s_{k}$. Thus, given the feasible allocation $(p, x)$, the arrays of $b_{j}$ 's individual payoffs $u_{j k}$ 's, defined for all $s_{k} \in C\left(b_{j}, x\right)$, and the corresponding $s_{k}$ 's individual payoffs $v_{j k}$ 's, with $b_{j} \in C\left(s_{k}, x\right)$, determine a feasible payoff vector $(u, v)$ and $(u, v ; x)$ is called a feasible outcome. We say that $x$ is compatible with $(u, v)$. Given a feasible outcome $(u, v ; x)$, we denote $\min _{k}\left\{u_{j k}\right\}$ and $\min _{j}\left\{v_{j k}\right\}$ the smallest individual payoff of buyer $b_{j}$ and seller $s_{k}$, respectively: $\min _{k}\left\{u_{j k}\right\}=\operatorname{Min}\left\{u_{j k} ; s_{k} \in C\left(b_{j}, x\right)\right\}, \min _{j}\left\{v_{j k}\right\}=\operatorname{Min}\left\{v_{j k} ; b_{j} \in C\left(s_{k}, x\right)\right\} .{ }^{12}$

\footnotetext{
${ }^{11}$ For any set $A \subseteq B \cup S$, we use the notation $\sum_{A}$ for the sum over all elements in $A$.

$12 \min _{k}\left\{u_{j k}\right\}$ and $\min _{j}\left\{v_{j k}\right\}$ can depend on the maching $x$. However, as shown in Sotomayor (1992), (1999), they are independent of the matching for competitive equilibrium outcomes. For notational simplicity, we do not include a reference to the matching $x$ in the expressions $\min _{k}\left\{u_{j k}\right\}$ and $\min _{j}\left\{v_{j k}\right\}$.
} 
Then, given a price vector $p$, buyer $b_{j} \in B$ has preferences over the admissible sets of objects that are completely described by the numbers $a_{j k}$ 's: For any two admissible sets of objects $S^{\prime}$ and $S^{\prime}$, buyer $b_{j}$ prefers $S^{\prime}$ to $S^{\prime \prime}$ at prices $p$ if $\sum s^{\prime}\left(a_{j k}-p_{k}\right)>\sum S^{\prime},\left(a_{j k}-p_{k}\right)$. She is indifferent between these sets if $\sum s^{\prime}\left(a_{j k}-p_{k}\right)=$ $\sum s^{\prime}\left(a_{j k}-p_{k}\right)$. We denote by $D\left(b_{j}, p\right)$ the set of admissible sets of objects that buyer $b_{j}$ most prefers at a given feasible price vector $p$ and we call it the demand set of buyer $b_{j}$ at $p$. In this context, $D\left(b_{j}, p\right) \neq \varnothing$ for all $b_{j} \in B$. Also, if $S^{\prime} \in D\left(b_{j}, p\right)$ and $s_{k} \in S^{\prime}$, then $a_{j k}-p_{k} \geq 0$, so the trade is acceptable to $s_{k}$ and $b_{j}$.

A competitive equilibrium is a feasible price vector for the objects plus an allocation of each buyer to an admissible set of objects belonging to her demand set that respects the quotas of the sellers. Moreover, in a competitive equilibrium, the price of each unsold object is its value for his owner. Formally,

Definition 2.3. A competitive equilibrium for $M$ is a feasible allocation ( $p, x)$ such that (i) $C\left(b_{j}, x\right) \in D\left(b_{j}, p\right)$ for all $b_{j} \in B$; (ii) if object $s_{k}$ is left unsold, then $p_{k}=r_{k}$.

If the allocation $(p, x)$ is a competitive equilibrium, we say that $p$ is an equilibrium price vector, $x$ is a competitive matching, and $x$ is compatible with $p$ and vice-versa. The outcome $(u, v ; x)$ corresponding to $(p, x)$ is called a competitive equilibrium outcome and $(u, v)$ is called a competitive equilibrium payoff compatible with $x$. Sotomayor (1992 and 1999) has shown that every competitive matching is optimal and that every optimal matching is compatible with any competitive equilibrium payoff. These results imply, in particular, that all competitive equilibria are Pareto optimal.

The next proposition, whose proof is immediate, provides an alternative characterization of competitive equilibria. It implies, in particular, that every seller sells all of his items for the same price

Proposition 2.1. The outcome $(u, v ; x)$ is a competitive equilibrium for $M$ if and only if it is feasible and (i) $v_{j k}=\min _{j}\left\{v_{j k}\right\}$ for all $b_{j} \in C\left(s_{k}, x\right)$, (ii) $\min _{k}\left\{u_{j k}\right\}+\min _{j}\left\{v_{j k}\right\} \geq a_{j k}$ $-r_{k}$ for all pairs $\left(b_{j}, s_{k}\right)$ with $x_{j k}=0$ and (iii) $\min _{k}\left\{u_{j k}\right\} \geq 0$ and $\min _{j}\left\{v_{j k}\right\} \geq 0$ for all $b_{j} \in B$ and $s_{k} \in S$.

Sotomayor (2007) proves that the set of competitive equilibrium payoffs is a complete lattice, under the partial order relation defined by the preferences of the 
sellers. Moreover, there is a conflict of interests between buyers and sellers with respect to two comparable competitive equilibrium payoffs. Thus, two particularly interesting outcomes in the set of competitive equilibrium outcomes exist:

Definition 2.4 A competitive equilibrium payoff is called a buyer-optimal competitive equilibrium payoff if every buyer weakly prefers it to any other competitive equilibrium payoff. We define a seller-optimal competitive equilibrium payoff similarly.

The unique competitive price vector corresponding to the buyer-optimal (respectively, seller-optimal) competitive equilibrium payoff is smaller (respectively, larger) in each component than any other competitive price vector. It is called the minimum competitive price vector (respectively, maximum competitive price vector) and we denote it by $\underline{p}$ (respectively, $\bar{p})$. Also, we let $(\bar{u}, \underline{p}-r)$ and $(\underline{u}, \bar{p}-r)$ be the buyer-optimal and the seller-optimal competitive equilibrium payoffs.

\section{COMPETITIVE EQUILIBRIUM RULES}

For a given set of agents and arrays of quotas $\left(B, S, t_{B}, t_{S}\right)$, a competitive equilibrium rule is a function that selects a unique competitive equilibrium allocation for every market, that is, for every possible valuation matrix for the buyers $a$ and valuation vector for the sellers $r$. We denote the market by $M(a, r)$. For each such market, the competitive equilibrium rule selects an equilibrium price vector $\Pi(a, r)$ and a competitive matching $X(a, r)$. Hence, we denote the competitive equilibrium rule by $(\Pi, X)$ and the competitive equilibrium selected by the rule when it is applied to $M(a, r)$ by $(\Pi(a, r), X(a, r))$. The corresponding buyers' and sellers' payoff vectors are denoted by $u(a, r)$ and $v(a, r)$. Then, for all $\left(b_{j}, s_{k}\right) \in B \mathrm{x} S, u(a, r)_{j k}=a_{j k}-\Pi(a, r)_{k}$ and $v(a, r)_{j k}=\Pi(a, r)_{k}-r_{k}$ if $X(a, r)_{j k}>0$.

If the competitive equilibrium rule $(\Pi, X)$ produces the buyer-optimal (respectively, seller-optimal) competitive equilibrium for every $M(a, r)$, the rule is called the buyer-optimal (respectively, seller-optimal) competitive equilibrium rule.

When a competitive equilibrium rule $(\Pi, X)$ is adopted in a market $M(a, r)$ and the agents are requested to report their valuations, then the rule induces a strategic game $\Gamma(\Pi, X, a, r)$, where the set of players is the set of agents $B \cup S$; the profile of valuations is given by $(a, r)$; the set of strategies for buyer $b_{j} \in B-b_{0}$ is the set of vectors $a_{j}^{\prime} \in R^{m}{ }_{+}$, with $a_{0}^{\prime}=0$; the set of strategies for seller $s_{k} \in S-s_{0}$ is the set of numbers $r^{\prime}{ }_{k} \geq 0$, with $r_{0}^{\prime}=0$; and the outcome function applied to the profile of strategies 
$\left(a^{\prime}, r^{\prime}\right)$ is given by $\left(\Pi\left(a^{\prime}, r^{\prime}\right), X\left(a^{\prime}, r^{\prime}\right)\right)$. We say that the game $\Gamma(\Pi, X, a, r)$ is the strategic game induced by $(\Pi, X)$ in market $M(a, r)$. The preferences of the players are determined by their true valuations $(a, r) .{ }^{13}$ Thus, the true individual payoffs in the transaction between buyer $b_{j}$ and seller $s_{k}$ at allocation $\left(\Pi\left(a^{\prime}, r^{\prime}\right), X\left(a^{\prime}, r^{\prime}\right)\right)$ are:

$$
\begin{aligned}
& U_{j k}\left(\Pi\left(a^{\prime}, r^{\prime}\right), X\left(a^{\prime}, r^{\prime}\right) ; a, r\right)=a_{j k}-\Pi_{k}\left(a^{\prime}, r^{\prime}\right) \text { if } X\left(a^{\prime}, r^{\prime}\right)_{j k}=1 \text { and } s_{k} \neq s_{0}, \\
& U_{j k}\left(\Pi\left(a^{\prime}, r^{\prime}\right), X\left(a^{\prime}, r^{\prime}\right) ; a, r\right)=0 \text { if } X\left(a^{\prime}, r^{\prime}\right)_{j k}=1 \text { and } s_{k}=s_{0}, \\
& V_{j k}\left(\Pi\left(a^{\prime}, r^{\prime}\right), X\left(a^{\prime}, r^{\prime}\right) ; a, r\right)=\Pi_{k}\left(a^{\prime}, r^{\prime}\right)-r_{k} \text { if } X\left(a^{\prime}, r^{\prime}\right)_{j k}=1 \text { and } b_{j} \neq b_{0} \text { and } \\
& V_{j k}\left(\Pi\left(a^{\prime}, r^{\prime}\right), X\left(a^{\prime}, r^{\prime}\right) ; a, r\right)=0 \text { if } X\left(a^{\prime}, r^{\prime}\right)_{j k}=1 \text { and } b_{j}=b_{0} .
\end{aligned}
$$

Therefore, buyer $b_{j}$ prefers allocation $\left(\Pi\left(a^{\prime}, r^{\prime}\right), X\left(a^{\prime}, r^{\prime}\right)\right)$ to allocation $(\Pi(a, r), X(a, r))$ if

$$
\sum_{C\left(b_{j}, X\left(a^{\prime}, r^{\prime}\right)\right)} U_{j k}\left(\Pi\left(a^{\prime}, r^{\prime}\right), X\left(a^{\prime}, r^{\prime}\right) ; a, r\right)>\sum_{C\left(b_{j}, X(a, r)\right)} U_{j k}(\Pi(a, r), X(a, r) ; a, r)
$$

and seller $s_{k}$ prefers allocation $\left(\Pi\left(a^{\prime}, r^{\prime}\right), X\left(a^{\prime}, r^{\prime}\right)\right)$ to allocation $(\Pi(a, r), X(a, r))$ if

$$
\sum_{C\left(s_{k}, X(a, r)\right)} V_{j k}\left(\Pi\left(a^{\prime}, r^{\prime}\right), X\left(a^{\prime}, r^{\prime}\right) ; a, r\right)>t\left(s_{k}\right)\left(\Pi_{k}(a, r)-r_{k}\right) .
$$

Definition 3.1. Agent $y \in\left(B-b_{0}\right) \cup\left(S-S_{0}\right)$ can manipulate the competitive equilibrium rule $(\Pi, X)$ in the market $M(a, r)$ if there is a profile of valuations $\left(a^{\prime}, r^{\prime}\right)$, which differs from $(a, r)$ only in agent $y$ 's valuations, such that agent $y$ is better off at allocation $\left(\Pi\left(a^{\prime}, r^{\prime}\right), X\left(a^{\prime}, r^{\prime}\right)\right)$ than at allocation $(\Pi(a, r), X(a, r))$.

We say that a competitive equilibrium rule is strategy-proof for the buyers (respectively, strategy-proof for the sellers) if there is no buyer (respectively, seller) who can manipulate the rule in any market.

\section{THE NON-MANIPULABILITY THEOREMS}

According to the Non-Manipulability Theorem for the assignment game (Demange 1982; Leonard 1983), ${ }^{14}$ the buyer-optimal (respectively, seller-optimal) competitive equilibrium rule is strategy-proof for the buyers (respectively, sellers). In this section, we use examples to show that this theorem does not extend to the many-to-many market. On the other hand, we prove that no seller can manipulate the seller-optimal competitive equilibrium rule in markets where each seller only has one object to sell, even though the buyers may want to acquire more than one object; and similarly for the buyers. Indeed, we prove a stronger result that asserts that no group of agents with a

\footnotetext{
${ }^{13}$ We will use "primes" to denote reported variables. For example, $a$ is the true valuation matrix of the buyers, whereas $a$ ' is the reported valuation matrix of the buyers.

${ }^{14}$ See also Demange and Gale (1985).
} 
quota of one can manipulate a rule that gives them their most-preferred competitive equilibrium payoff.

Example 4.1 illustrates a situation in which the seller-optimal competitive equilibrium rule is manipulated by a seller who does not sell all his objects following manipulation. We will show that this feature of our example is key.

Example 4.1. Consider the market $M(a, r)$, where $B=\left\{b_{1}, b_{2}, b_{0}\right\}, \quad S=\left\{s_{1}, s_{0}\right\}$, $a_{11}=3, \quad a_{21}=1, \quad t\left(b_{1}\right)=t\left(b_{2}\right)=1, \quad t\left(s_{1}\right)=2$, and $r_{1}=0$. At the seller-optimal competitive equilibrium allocation, seller $s_{1}$ sells his two objects at a price of 1 , so his total payoff is 2 . However, if he misrepresents his valuation and reports $r^{\prime}{ }_{1}=2.5$ then, at any competitive equilibrium allocation for $M\left(a, r^{\prime}\right)$, he only sells one object, to buyer $b_{1}$, and obtains a true payoff of 2.5. Therefore, $s_{1}$ can manipulate the seller-optimal competitive equilibrium rule.

Similarly, Example 4.2 shows that there are markets where the buyers may have incentives not to report their true valuations if the buyer-optimal competitive equilibrium rule is applied.

Example 4.2. Consider the market $M(a, r)$ with $B=\left\{b_{1}, b_{2}, b_{0}\right\}, S=\left\{s_{1}, s_{2}, s_{3}, s_{0}\right\}$, $a_{1}=(7,6,4,0), a_{2}=(8,6,3,0), r_{1}=r_{2}=r_{3}=0, t\left(b_{1}\right)=2$ and $t\left(b_{2}\right)=t\left(s_{1}\right)=t\left(s_{2}\right)=$ $t\left(s_{3}\right)=1$. Under the buyer-optimal competitive equilibrium, buyer $b_{1}$ is matched to $s_{2}$ and $s_{3}$ and she receives individual payoffs of 5 and 4 from these transactions, whereas buyer $b_{2}$ is matched to $s_{1}$ and receives a payoff of 5 . But if buyer $b_{1}$ reports $a_{1}{ }^{\prime}=(7,6,7,0)$ then, under the new buyer-optimal competitive equilibrium, $b_{1}$ pays 0 to sellers $s_{2}$ and $s_{3}$. Hence, she gets 6 and 4 under her true individual payoffs instead of 5 and 4 and she has an incentive to misrepresent her valuations.

In Example 4.2, buyer $b_{1}$ can manipulate the rule because she buys two objects and she can influence the price of one of the objects $\left(s_{2}\right)$ by reporting a different valuation for some other object $\left(s_{3}\right)$. We will show that a buyer with a quota of one does not have an incentive to manipulate any competitive equilibrium rule in a market where she obtains her most-preferred competitive equilibrium payoff; in particular, she never has an incentive to manipulate the buyer-optimal competitive equilibrium rule.

Theorem 4.1 states a general non-manipulability result. It considers deviations by groups of buyers and sellers. It asserts that if a group of agents with a quota of one 
misrepresents their valuation then at least one of the agents would be as well-off under her/his most preferred competitive equilibrium outcome for the true market than in the outcome selected by the rule for the reported market.

Theorem 4.1. Consider a market $M(a, r)$ and a vector of reported valuations $\left(a^{\prime}, r^{\prime}\right)$. Let $B^{\prime} \cup S^{\prime}$ be the set of agents who misrepresent their valuations, where $B^{\prime} \subseteq B$, $S^{\prime} \subseteq S$, and suppose that $t\left(b_{j}\right)=1$ and $t\left(s_{k}\right)=1$ for all $b_{j} \in B^{\prime}$ and all $s_{k} \in S^{\prime}$. Let ( $\left.u^{\prime}, v^{\prime} ; x^{\prime}\right)$ be any competitive equilibrium outcome for the market $M\left(a^{\prime}, r^{\prime}\right)$ and $\left(U, V ; x^{\prime}\right)$ the true outcome under ( $\left.u^{\prime}, v^{\prime} ; x^{\prime}\right)$. Then, there exists a competitive equilibrium outcome $(u, v ; x)$ for $M(a, s)$ such that either $\sum_{k} u_{j k} \geq \sum_{k} U_{j k}$ for at least one $b_{j} \in B^{\prime}$ or $\sum_{j} v_{j k} \geq \sum_{j} V_{j k}$ for at least one $s_{k} \in S^{\prime}$.

Proof. The proof of Theorem 4.1 requires some preliminaries.

Consider $M(\underline{a}) \equiv M(a, r)$, where $\underline{a}_{j k}=\max \left\{a_{j k}-r_{k}, 0\right\}$ for all $\left(b_{j}, s_{k}\right) \in B \times S$. We define a market related to $M(\underline{a})$ in which each buyer $b_{j}$ (resp., each seller $s_{k}$ ) with a quota $t\left(b_{j}\right)$ (resp., $t\left(s_{k}\right)$ ) is "replicated" $t\left(b_{j}\right)$ (resp., $t\left(s_{k}\right)$ ) times so that each nondummy agent has a quota of one in the new market. We denote $b_{j(q)}\left(\right.$ resp., $\left.s_{k(h)}\right)$ the $q$-th (resp., $h$-th) copy of $b_{j}$ (resp., $\left.s_{k}\right), B \# \equiv\left\{b_{j(1)}, b_{j(2)}, \ldots, b_{j\left(t\left(b_{j}\right)\right)} ; b_{j} \in B-b_{0}\right\} \cup\left\{b_{0}\right\}$ and $S \# \equiv\left\{s_{k(1)}, \ldots, s_{k\left(t\left(s_{k}\right)\right) ;} ; s_{k} \in S-s_{0}\right\} \cup\left\{s_{0}\right\}$. Also, let $t\left(b_{j(q)}\right)=1$ and $t\left(s_{k(h)}\right)=1$ for all $b_{j(q)} \in B \#-b_{0}$ and $s_{k(h)} \in S \#-s_{0}$.

In the proof, we use the following simplification. If some agent, say buyer $b_{j}$, has a quota of one, then we will identify her individual payoff $u_{j k}$ under $(u, v)$ with her array of individual payoffs $u_{j}=\left\{u_{j k}\right\}$, and we will refer to $u_{j}$ as $b_{j}$ 's payoff under $(u, v)$.

For each feasible matching $x$ for the market $M(\underline{a})$, Definition 4.1 proposes a related feasible matching $x \#$ for the market where the players are $B \#$ and $S \#$. The idea is to define a matching $x \#$ such that if a buyer $b_{j}$ buys $s_{k}$ at $x$, then one (and only one) copy of $b_{j}$, say $b_{j(q)}$, buys one copy of $s_{k}$, say $s_{k(h)}$, under $x \#$. Moreover, no other pair in $B \# \mathrm{x} S \#$ can enter a partnership at $x \#$, that is, if $b_{j}$ does not buy $s_{k}$ at $x$, then no copy of $b_{j}$ buys any copy of $s_{k}$ at $x \#$.

Definition 4.1. Let $x$ be a feasible matching for $B$ and $S$. The $x$-related matching $x \#$ for $B \#$ and $S \#$ is defined as the matching that satisfies the following conditions:

(i) if $x_{j k}=1$ then $\sum_{q, h} x \#_{j(q) k(h)}=1$;

(ii) if $x_{j k}=0$ then $\sum_{q, h} x \#_{j(q) k(h)}=0$;

(iii) $\sum_{B \#} x \#_{j(q) k(h)}=1$ for all $s_{k(h)} \in S \#$ and $\sum_{S \#} x \#_{j(q) k(h)}=1$ for all $b_{j(q)} \in B \#$. 
For each pair $(\underline{a}, x)$, where $x$ is an optimal matching for $M(\underline{a})$, we define the $|B \#| \mathrm{x}|S \#|-m a t r i x \quad \underline{a} \#$ by

$$
\underline{a} \#_{j(q) k(h)}=0 \text { if } x_{j k}=1 \text { but } x \#_{j(q) k(h)}=0 ; \underline{a}_{j(q) k(h)}=\underline{a}_{j k} \text { otherwise. }
$$

The functional relation defined above is denoted by $\varphi(\underline{a}, x)$ and the related market is $M(\underline{a} \#)$. Clearly, $x \#$ is an optimal matching for $M(\underline{a} \#)$.

The following Key lemma is due to Sotomayor (1992).

Lemma 4.1 (Key Lemma). Let $x$ be an optimal matching for $M(\underline{a})$. Let $x \#$ be the $x$-related matching and $\underline{a} \#=\varphi(\underline{a}, x)$. Consider a feasible matching $x$, for $M(\underline{a})$. Then there exists a feasible matching $x$ '\# for $M(\underline{a} \#)$ such that

(i) if $x^{\prime}{ }_{j k}=1$ then:

(ia) $\sum_{q, h} x^{\prime} \#_{j(q) k(h)}=1$;

(ib) for the replicas $(j(q), k(h))$ for which $x^{\prime} \#_{j(q) k(h)}=1$ it holds that

$$
\underline{a} \#_{j(q) k(h)}=\underline{a}_{j k}
$$

(ic) if additionally $x_{j k}=1$ then $x^{\prime} \#_{j(q) k(h)}=1$ if and only if $x \#_{j(q) k(h)}=1$;

(ii) if $x_{j k}^{\prime}=0$ then $\sum_{q, h} x^{\prime} \#_{j(q) k(h)}=0$;

(iii) $\sum_{B \#} x^{\prime} \#_{j(q) k(h)}=1$ for all $s_{k(h)} \in S \#$ and $\Sigma_{S \#} x^{\prime} \#_{j(q) k(h)}=1$ for all $b_{j(q)} \in B \#$.

The matching $x$ '\# defined in Lemma 4.1 is an $x$ '-related matching. It can be easily shown that $x^{\prime}$ is optimal for $M(\underline{a})$ if and only if $x^{\prime} \#$ is optimal for $M(\underline{a} \#)$.

The connection between the feasible outcomes and the competitive equilibrium outcomes for $M(\underline{a} \#)$ and $M(\underline{a})$ is given by Lemma 4.2. below. (The proofs of the lemmas are in the Appendix.)

Lemma 4.2. Let $x$ be an optimal matching for $M(\underline{a})$, $x \#$ the matching obtained from $x$ by Definition 4.1, and $\underline{a} \#=\varphi(\underline{a}, x)$. Also, let $x$ ' be a feasible matching for $M(\underline{a})$ and $x$ '\# the x'-related matching defined by the Key Lemma. Consider the outcome $\left(u^{\prime}, v^{\prime} ; x^{\prime}\right)$ for $M(\underline{a})$ and the outcome (u'\#, v'\#; $\left.x^{\prime} \#\right)$ for $M(\underline{a} \#)$ and suppose that they satisfy the following relations: (1) for all pairs $\left(b_{j(q)}, s_{k(h)}\right) \in B \# x S \#$ such that $x^{\prime} \#_{j(q) k(h)}$ $=1$ then $u^{\prime} \#_{j(q)}=u_{j k}^{\prime}$ and $v^{\prime} \#_{k(h)}=v_{j k}^{\prime}$; (2) for all $b_{j(q)} \in B \#\left(\right.$ resp., $\left.s_{k(h)} \in S \#\right)$ such that $x^{\prime} \#_{j(q) 0}=1 \quad\left(\operatorname{resp} ., x^{\prime} \#_{0 k(h)}=1\right)$ then $u^{\prime} \#_{j(q)}=u_{j 0}^{\prime}=0 \quad\left(\operatorname{resp} ., v^{\prime} \#_{k(h)}=v^{\prime}{ }_{0 k}=0\right)$. Then,

(i) (u', v'; $\left.x^{\prime}\right)$ is a feasible outcome for M(a) if and only if (u'\#, v'\#; $\left.x^{\prime} \#\right)$ is a feasible outcome for $M(\underline{a} \#)$;

(ii) if $\left(u^{\prime}, v^{\prime} ; x^{\prime}\right)$ is a competitive equilibrium outcome for $M(\underline{a})$, then ( $\left.u^{\prime} \#, v^{\prime} \# ; x^{\prime} \#\right)$ is a competitive equilibrium outcome for $M(\underline{a} \#)$; 
(iii) if ( $\left.u^{\prime} \#, v^{\prime} \# ; x^{\prime} \#\right)$ is a competitive equilibrium outcome for $M(\underline{a} \#)$ and $v^{\prime} \#_{k(1)}=v^{\prime} \#_{k(2)}=\ldots=v^{\prime} \#_{k\left(t\left(s_{k}\right)\right)}$ for all $s_{k} \in S$, then $\left(u^{\prime}, v^{\prime} ; x^{\prime}\right)$ is a competitive equilibrium outcome for $M(\underline{a})$.

Lemma 4.2 does not relate the seller-optimal competitive equilibrium payoff of $M(\underline{a} \#)$ and the seller-optimal competitive equilibrium payoff of $M(\underline{a})$. Lemma 4.3 states that the sellers with a quota of one have the same payoff in both outcomes.

Lemma 4.3. Let $(\underline{u}, \bar{v} ; x)$ be a seller-optimal competitive equilibrium outcome for $M(\underline{a})$ and $(u, v ; x \#)$ be a seller-optimal competitive equilibrium outcome for $M(\underline{A} \#)$, where $\underline{a} \#=\varphi(\underline{a}, x)$. Then, $\bar{v}_{k}=v_{k}$ for all $s_{k} \in S$ with $t\left(s_{k}\right)=1$.

Lemma 4.4 (Blocking Lemma). Let $(u, v ; x)$ be a feasible outcome for $M($ a\#) and

$$
B+\equiv\left\{b_{j(q)} \in B \# ; u_{j(q)}>u_{j(q)}^{+}\right\}, S+\equiv\left\{s_{k(h)} \in S \# ; v_{k(h)}>v^{+}{ }_{k(h)}\right\},
$$

where $\left(u^{+}, v^{-}\right)$and $\left(u^{-}, v^{+}\right)$are the buyer-optimal and the seller-optimal competitive equilibrium payoffs for $M(a \#)$, respectively. If $(B+\cup S+) \neq \varnothing$ then there exist $b_{j(q)} \in$ $B \#-B+$ and $s_{k(h)} \in S \#-S+$ such that $\left(b_{j(q)}, s_{k(h)}\right)$ blocks $(u, v ; x)$.

Our last lemma is an immediate consequence of Corollary 1 of Sotomayor (2007).

Lemma 4.5. Let $(\underline{u}, \bar{v} ; x)$ be a buyer-optimal competitive equilibrium outcome for $M(\underline{a})$ and $(u, v ; x \#)$ the related competitive equilibrium outcome for $M(\underline{a} \#)$ according to Lemma 4.2, where $\underline{a} \#=\varphi(\underline{a}, x)$. Then, $(u, v ; x \#)$ is a buyer-optimal competitive equilibrium outcome for $M(\underline{a} \#)$.

We can now proof Theorem 4.1. Denote $\underline{a}_{j k}=\max \left\{a_{j k}^{\prime}-r^{\prime}{ }_{k}, 0\right\}$ for all $\left(b_{j}, s_{k}\right) \in$ $B \mathrm{x} S$ and let $(\bar{u}, \underline{v} ; x)$ and $(\underline{u}, \bar{v} ; x)$ be a buyer-optimal and seller-optimal competitive equilibrium outcomes for $M(\underline{a})$. Suppose that $B^{\prime} \cup S^{\prime} \neq \varnothing$ and all agents in $B^{\prime} \cup S^{\prime}$ are strictly better off at $\left(u^{\prime}, v^{\prime} ; x^{\prime}\right)$ than at any competitive equilibrium outcome for the original market $M(\underline{a})$. Then, $U_{j}>\bar{u}_{j}$ for all $b_{j} \in B^{\prime}$ and $V_{k}>\bar{v}_{k}$ for all $s_{k} \in S^{\prime}$.

We claim that $\left(U, V ; x^{\prime}\right)$ is pairwise-feasible for $M(\underline{a})$. In fact, if $x^{\prime}{ }_{j k}=1$ then

$$
\begin{aligned}
& U_{j k}=u_{j k}^{\prime} \geq 0 \text { if } b_{j} \notin B^{\prime} ; \\
& U_{j k}=U_{j}>\bar{u}_{j} \geq 0 \text { if } b_{j} \in B^{\prime} ; \\
& V_{j k}=v^{\prime}{ }_{j k} \geq 0 \text { if } s_{k} \notin S^{\prime} ; \\
& V_{j k}=V_{k}>\bar{v}_{k} \geq 0 \text { if } s_{k} \in S^{\prime} .
\end{aligned}
$$

Therefore, $0 \leq U_{j k}+V_{j k}=\left(a_{j k}-v^{\prime}{ }_{j k}-r_{k}{ }_{k}\right)+\left(v^{\prime}{ }_{j k}+r^{\prime}{ }_{k}-r_{k}\right)=a_{j k}-r_{k}$. Then, $a_{j k}-r_{k} \geq 0$ which implies that $\underline{a}_{j k}=a_{j k}-r_{k}$ and $U_{j k}+V_{j k}=\underline{a}_{j k}$. Thus, $\left(U, V ; x^{\prime}\right)$ is pairwisefeasible for $M(\underline{a})$. Consequently, $\left(U, V ; x^{\prime}\right)$ is feasible for $M(\underline{a})$.

Let $\underline{a} \#=\varphi(\underline{a}, x)$. Since $x^{\prime}$ is feasible for $M(\underline{a})$, the Key Lemma implies that there exists a feasible matching $x^{\prime} \#$ for $M(\underline{a} \#)$ related to $x^{\prime}$ such that if $x_{j k}^{\prime}=1$ then for 
some $b_{j(q)} \in B \#$ and $s_{k(h)} \in S \#$ it happens that $x^{\prime} \#_{j(q) k(h)}=1$ and $\underline{a}_{j(q) k(h)}=\underline{a}_{j k}$. Let (U\#, $\left.V \#, x^{\prime} \#\right)$ be the feasible outcome in $M(\underline{a} \#)$ related to $\left(U, V ; x^{\prime}\right)$ according to Lemma 4.2. Also, let $(\bar{u} \#, \underline{v} \# ; x \#)$ and $(\underline{u} \#, \bar{v} \# ; x \#)$ be the competitive equilibrium outcomes related to $(\bar{u}, \underline{v} ; x)$ and $(\underline{u}, \bar{v} ; x)$, respectively, according to Lemma 4.2. Now take $B+$ and $S+$ as defined in Lemma 4.4:

$$
\left.\left.B+\equiv\left\{b_{j(q)} \in B \# ; U \#_{j(q)}\right)>u_{j(q)}^{+}\right)\right\} \text {and } S+\equiv\left\{s_{k(h)} \in S \# ; V \#_{k(h)}>v_{k(h)}^{+}\right\},
$$

where $\left(u^{+}, v^{-}\right)$and $\left(u^{-}, v^{+}\right)$are the buyer-optimal and the seller-optimal competitive equilibrium payoffs for $M(\underline{a} \#)$, respectively.

Lemma 4.5 implies that $(\bar{u} \#, \underline{v} \# ; x \#)=\left(u^{+}, v^{-} ; x \#\right)$. By hypothesis, $U_{j}>\bar{u}_{j}$ if $b_{j} \in B^{\prime}$. Then, by identifying $b_{j}$ with his single copy $b_{j(1)}$ we can write $U \#_{j}=U_{j}>\bar{u}_{j}=$ $\bar{u} \#_{j}=u_{j}^{+}$. Thus, if $B^{\prime} \neq \varnothing$ then $B^{\prime} \subseteq B+$ and so $B+\cup S+\neq \varnothing$.

If $B^{\prime}=\varnothing$ then $S^{\prime} \neq \varnothing$. Since $t\left(s_{k}\right)=1$ for all $s_{k} \in S^{\prime}$, it follows from Lemma 4.3 that $\bar{v}_{k}=v_{k}^{+}$for all $s_{k} \in S^{\prime}$. Then, $S^{\prime} \subseteq S+$ and so $B+\cup S+\neq \varnothing$.

Therefore, we can apply Lemma 4.4 and there exists a pair $\left(b_{j(q)}, s_{k(h)}\right) \in(B \#-B+)$ $\mathrm{x}(S \#-S+)$ with $x^{\prime} \#_{j(q) k(h)}=0$ such that $U \#_{j(q) f(z)}+V \#_{g(y) k(h)}<\underline{a}_{j(q) k(h)}$ where $\{f(z)\}=$ $\mathrm{C}\left(b_{j(q)}, x^{\prime} \#\right)$ and $\{g(y)\}=\mathrm{C}\left(s_{k(h)}, x^{\prime} \#\right)$. Since $b_{j}$ is not in $B^{\prime}$ and $s_{k}$ is not in $S^{\prime}$ we have that these agents did not misrepresent their valuations. Then,

$$
\begin{aligned}
& U \#_{j(q) f(z)}=U_{j f}=u_{j f}^{\prime}, \\
& V^{\prime} \#_{g(y) k(h)}=V_{g k}=v^{\prime}{ }_{g k}, \text { and } \\
& \underline{a}_{j k}=\underline{a}^{\prime}{ }_{j k} .
\end{aligned}
$$

Given that either $\underline{a}_{j(q) k(h)}=\underline{a}_{j k}$ or $\underline{a}_{j(q) k(h)}=0$, it follows that $\underline{a}_{j(q) k(h)} \leq \underline{a}_{j k}=\underline{a}_{j k}^{\prime}$. Thus, $0 \leq \min _{k}\left\{u^{\prime}{ }_{j k}\right\}+\min _{j}\left\{v^{\prime}{ }_{j k}\right\} \leq u_{j f}^{\prime}+v^{\prime}{ }_{g k}=U \#_{j(q) f(z)}+V \#_{g(y) k(h)}<\underline{a}_{j(q) k(h)} \leq \underline{a}_{j k}^{\prime}=a^{\prime}{ }_{j k}-r^{\prime}{ }_{k}$, where the last equality follows from the fact that $\underline{a}_{j k}>0$. But then $\min _{k}\left\{u_{j k}\right\}+$ $\min _{j}\left\{v_{j k}^{\prime}\right\}<a_{j k}^{\prime}-r^{\prime}{ }_{k}$, which contradicts the fact that $\left(u^{\prime}, v^{\prime} ; x^{\prime}\right)$ is a competitive equilibrium outcome for $M\left(a^{\prime}, r^{\prime}\right)$.

Theorem 4.1 is a strong result in the sense that it provides information about any possible deviation by any group of agents with a quota of one. It leads to results on the incentives to manipulate of individual agents with a quota of one. It also allows us to derive results concerning the strategy-proofness of certain rules in many-to-one and one-to-many markets.

Theorem 4.2 states the first consequence of Theorem 4.1: no seller with a quota of one can manipulate in $M(a, r)$ any competitive equilibrium rule $(\Pi, X)$ that associates $(a, r)$ with a competitive equilibrium that gives the seller his optimal competitive equilibrium payoff. Similarly, no buyer with a quota of one can manipulate any 
competitive equilibrium rule $(\Pi, X)$ that associates $(a, r)$ with a competitive equilibrium that gives the buyer her optimal competitive equilibrium payoff. We note that it is not required that $(\Pi, X)$ is the seller-optimal, respectively the buyer-optimal, competitive equilibrium rule.

Theorem 4.2. Let $M=M(a, r)$ be a market and $(\Pi, X)$ a competitive equilibrium rule.

(i) Consider $s_{k} \in S$ with $t\left(s_{k}\right)=1$. If the competitive equilibrium outcome associated with $(\Pi(a, r), X(a, r))$ gives $s_{k}$ his most-preferred competitive equilibrium payoff then $s_{k}$ cannot manipulate (П, X). In particular, $s_{k}$ cannot manipulate the seller-optimal competitive equilibrium rule in $M$.

(ii) Consider $b_{j} \in B$ with $t\left(b_{j}\right)=1$. If the competitive equilibrium outcome associated with $(\Pi(a, r), X(a, r))$ gives $b_{j}$ her most-preferred competitive equilibrium payoff then $b_{j}$ cannot manipulate $(\Pi, X)$. In particular, $b_{j}$ cannot manipulate the buyer-optimal competitive equilibrium rule in $M$.

Proof. The proof follows directly from Theorem 4.1 by considering $S^{\prime}=\left\{s_{k}\right\}$ and $B^{\prime}=\varnothing$ in $(i)$, and $S^{\prime}=\varnothing$ and $B^{\prime}=\left\{b_{j}\right\}$ in $(i i)$.

As a corollary of Theorem 4.2, no seller can manipulate the seller-optimal competitive equilibrium rule in many-to-one models, that is, in markets where all sellers have a quota of one. Similarly, in markets where all buyers have a quota of one, no buyer can manipulate the buyer-optimal competitive equilibrium rule.

Corollary 4.1. (i) The seller-optimal competitive equilibrium rule is strategy-proof for the sellers in many-to-one buyer-seller markets.

(ii) The buyer-optimal competitive equilibrium rule is strategy-proof for the buyers in one-to-many buyer-seller markets.

Corollary 4.1 states that the competitive equilibrium rule which is optimal for one side of the market is individual strategy-proof for the agents in that side of the market. We can use Theorem 4.1 to go further and show that the rules are also group strategyproof. ${ }^{15}$ We now provide the precise definition of group strategy-proof for the sellers we are using in this paper. The definition of group strategy-proof for the buyers is similar.

\footnotetext{
${ }^{15}$ Barberà, Berga, and Moreno (2016) show the equivalence between individual strategy-proof and group strategy-proof if the domain and the rule satisfy three properties. We cannot use their results because our framework does not satisfy the properties.
} 
Definition 4.2. The rule $(\Pi, X)$ is manipulable in market $M(a, r)$ by coalition $S^{\prime} \subseteq S$ if there exists $r^{\prime}$ with $r^{\prime}{ }_{k}=r_{k}$ for all $s_{k} \in S-S$ ' such that all sellers in $S^{\prime}$ strictly prefer $\left(\Pi\left(a, r^{\prime}\right), X\left(a, r^{\prime}\right)\right)$ to $(\Pi(a, r), X(a, r))$. The rule $(\Pi, X)$ is group strategyproof for the sellers if it is not manipulable by any coalition $S^{\prime} \subseteq S$ in any $M(a, r)$.

Theorem 4.3. (i) The seller-optimal competitive equilibrium rule is group strategyproof for the sellers in many-to-one buyer-seller markets.

(ii) The buyer-optimal competitive equilibrium rule is group strategy-proof for the buyers in one-to-many buyer-seller markets.

Proof. (i) Consider the many-to-one buyer-seller markets, where all sellers have a quota of one, and suppose by contradiction that the seller-optimal competitive equilibrium rule is not group strategy-proof for the sellers. Then, there exist a market $M(a, r)$, a coalition $S^{\prime} \subseteq S$, and a vector of reported valuations $r^{\prime}$ with $r^{\prime}{ }_{k}=r_{k}$ for all $s_{k} \in S-S^{\prime}$ such that sellers in $S^{\prime}$ can manipulate the rule in $M(a, r)$ through $r^{\prime}$. Let $(\underline{u}, \bar{v} ; x)$ and $\left(u^{\prime}, v^{\prime} ; x^{\prime}\right)$ be the seller-optimal competitive equilibrium outcomes for, respectively, markets $M(a, r)$ and $M\left(a, r^{\prime}\right)$; and let $\left(U, V ; x^{\prime}\right)$ be the true outcome (for the sellers' true preferences) under $\left(u^{\prime}, v^{\prime} ; x^{\prime}\right)$. For the coalition $S^{\prime}$ to manipulate the rule in $M(a, r)$ through $r^{\prime}$, it is necessary that $\sum_{j} V_{j k}>\sum_{j} \bar{v}_{j k}$ for all $s_{k} \in S^{\prime}$. However, this contradicts Theorem 4.1, which ensures the existence of at least one seller $s_{k} \in S$, for whom $\sum_{j} \bar{v}_{j k} \geq \sum_{j} V_{j k}$.

(ii) The proof of (ii) is identical to that of (i).

We close this section with a result that helps understand why a buyer with a quota of one never has an incentive to manipulate the buyer-optimal competitive equilibrium rule. The result is interesting in itself because it shows that the payoff of a buyer with a quota of one in the buyer-optimal competitive equilibrium rule is the difference between the "total value" of the market and the "total value" of the market without that buyer. This result implies that, at the buyer-optimal competitive equilibrium allocation, the price charged to a buyer with a quota of one does not depend on his statement of valuation.

Theorem 4.4 requires some notation: For a market $M=M(a, r)$ and an optimal matching $x$ for $M$, we set $V(a, r) \equiv \sum_{B x S} \underline{a}(a, r)_{j k} x_{j k}$. Similarly, for the market $M_{-j}$ that involves the sets of agents $B-\left\{b_{j}\right\}$ and $S$ with the same valuations as in $M$, and an optimal matching $x^{\prime}$ for $M_{-j}$, we set $V_{-j}(a, r) \equiv \sum_{(B-\{b j\}) x S} \underline{a}(a, r)_{j k} x_{j k}$. 
Theorem 4.4. Let $(\bar{u}, \underline{v} ; x)$ be a buyer-optimal competitive equilibrium outcome for $M(a, r)$. Then, $\bar{u}_{j k}=V(a, r)-V_{-j}(a, r)$, for all $b_{j} \in B$ with $t\left(b_{j}\right)=1$ and $s_{k} \in S$ with $x_{j k}=1$.

Proof. We use the following lemma, which is proven in the Appendix:

Lemma 4.6. Let $(\bar{u}, \underline{v} ; x)$ be a buyer-optimal competitive equilibrium outcome for $M(a, r)$. Let $S^{\prime} \subseteq S$ with $S^{\prime} \neq \varnothing$ be such that $\underline{v}_{k}>0$ for all $s_{k} \in S^{\prime}$. Then, (i) $x\left(S-S^{\prime}\right) \neq\left\{b_{0}\right\}$ and (ii) there is a pair $\left(b_{j}, s_{k}\right) \in x\left(S-S^{\prime}\right) \mathrm{x} S^{\prime}$, with $b_{j} \neq b_{0}$ and $x_{j k}=0$, and a seller $s_{t} \in S-S^{\prime}$ with $x_{j t}=1$, such that $\bar{u}_{j t}+\underline{v}_{k}=a_{j k}-r_{k}$.

Construct a graph whose vertices are $B \cup S$ with two types of arcs. If $x_{j k}=0$ and $\min _{k}\left\{\bar{u}_{j k}\right\}+\underline{v}_{k}=a_{j k}-r_{k}$ there is an arc from $s_{k}$ to $b_{j}$; if $x_{j k}=1$ and $\min _{k}\left\{\bar{u}_{j k}\right\}=\bar{u}_{j k}$ there is an arc from $b_{j}$ to $s_{k}$. Let $b_{1} \in B$ such that $t\left(b_{1}\right)=1$. Let $s_{1} \in S$ such that $x_{11}=1$. Then there is an arc from $b_{1}$ to $s_{1}$. We claim that there is an oriented path starting from $b_{1}$ and ending at a seller with a zero payoff (this seller might be $s_{0}$ ). To see this, suppose there is no such a path. Let $B^{\prime} \cup S^{\prime}$ be all the vertices that can be reached by a directed path starting from $b_{1}$. Then, $\underline{v}_{k}>0$ for all $s_{k} \in S^{\prime}$, so $s_{0} \notin S^{\prime}$ and $b_{j} \neq b_{0}$ for all $b_{j} \in B^{\prime}$. Also, if $b_{j} \in B^{\prime}$ then $b_{j}$ fills her quota, since otherwise $\min _{k}\left\{\bar{u}_{j k}\right\}=\bar{u}_{j 0}=0$ and then there is an arc from $b_{j}$ to $s_{0}$, so $s_{0} \in S^{\prime}$, contradiction. By Lemma 4.1, $x\left(S-S^{\prime}\right) \neq b_{0}$ and there is a pair $\left(b_{j}, s_{k}\right) \in x\left(S-S^{\prime}\right) \times S^{\prime}$, with $b_{j} \neq b_{0}$ and $x_{j k}=0$, and $s_{t} \in S-S$ ' with $x_{j t}=1$, such that $\bar{u}_{j t}+\underline{v}_{k}=a_{j k}-r_{k}$. But then $a_{j k}-r_{k}=$ $\bar{u}_{j t}+\underline{v}_{k} \geq \min _{k}\left\{\bar{u}_{j k}\right\}+\underline{v}_{k} \geq a_{j k}-r_{k}$, so $\min _{k}\left\{\bar{u}_{j k}\right\}+\underline{v}_{k}=a_{j k}-r_{k}$ and there is an arc from $s_{k}$ to $b_{j}$, which implies that $b_{j} \in B$, and $\bar{u}_{j t}=\min _{k}\left\{\bar{u}_{j k}\right\}$, so there is an arc from $b_{j}$ to $s_{t}$, which implies that $s_{t} \in S$, which contradicts the fact that $s_{t} \in S-S$ '.

Now consider a directed path $c$ starting on $b_{1}$ and ending at a seller $s_{h}$ with a zero payoff (note that $s_{h}$ might be $\left.s_{1}\right)$. That is, $c=\left(b_{1}, s_{1}, b_{2}, s_{2}, b_{3}, \ldots, s_{h-1}, b_{h}, s_{h}\right)$, where $x_{d d}=1, \min _{k}\left\{\bar{u}_{d k}\right\}=\bar{u}_{d d}$ and $\min _{k}\left\{\bar{u}_{d k}\right\}+\underline{v}_{d-1}=a_{d d-1}-r_{d-1}$ for $d=1, \ldots, h$.

Take the matching $x^{\prime}$ in $M^{\prime}=M_{-1}(a, r)$ that assigns $s_{1}$ to $\left\{b_{2}\right\} \cup\left(C\left(s_{1}, x\right)-\left\{b_{1}\right\}\right)$, $s_{2}$ to $\left\{b_{3}\right\} \cup\left(C\left(s_{2}, x\right)-\left\{b_{2}\right\}\right), \ldots, \quad s_{h-1}$ to $\left\{b_{h}\right\} \cup\left(C\left(s_{h-1}, x\right)-\left\{b_{h-1}\right\}\right)$ and $s_{h}$ to $\left\{b_{0}\right\} \cup\left(C\left(s_{h}, x\right)-\left\{b_{h}\right\}\right)$ if $s_{h} \neq s_{0}$, and that otherwise agrees with $x$ on every agent in $B-\left\{b_{1}\right\} \cup S$ that is not in the path. Define $u^{*}$ as follows: if $b_{d} \in c$ and $b_{d} \neq b_{1}$ then $u_{d d-1}^{*}=\bar{u}_{d d}$ and $u_{d k}^{*}=\bar{u}_{d k}$ if $s_{k} \in C\left(b_{d}, x\right)-\left\{s_{d}\right\}$; if $b_{d} \notin c$. Thus, $u_{d k}^{*}=\bar{u}_{d k}$ if $s_{k} \in C\left(b_{d}, x\right)$. From the construction of $x^{\prime}$ and $u^{*}$ it follows that $\left(u^{*}, \underline{v} ; x^{\prime}\right)$ is a competitive equilibrium outcome for $M^{\prime}$, which implies that $x^{\prime}$ is an optimal matching for $M^{\prime}$. Therefore, $\sum_{b_{j} \neq b_{1}, s_{k} \in S} \underline{a}(a, r)_{j k} x_{j k}^{\prime}=V_{-1}(a, r)$. Then we can write

$$
\sum_{b_{j} \neq b_{1}, s_{k} \in S} \underline{a}(a, r)_{j k} x_{j k}^{\prime}=\sum_{b_{j} \in B-\left\{b_{1}\right\}, s_{k} \in C\left(b_{j}, x^{\prime}\right)} u_{j k}^{*}+\sum_{S} \underline{v}_{k}=
$$




$$
\sum_{b_{j} \in B-\left\{b_{1}\right\}, s_{k} \in C\left(b_{j}, x^{\prime}\right)} \bar{u}_{j k}+\sum_{S} \underline{v}_{k}=V(a, r)-\bar{u}_{11} .
$$

Hence, $\bar{u}_{11}=V(a, r)-V_{-1}(a, r)$.

According to Theorem 4.4, if $t\left(b_{j}\right)=1$ and $x_{j k}=1$ for $b_{j} \in B, s_{k} \in S$ and optimal matching $x$, then

$$
\underline{v}_{k}=\underline{a}(a, r)_{j k}-\bar{u}_{j k}=\underline{a}(a, r)_{j k}-V(a, r)+V_{-j}(a, r)=V_{-j}(a, r)-\sum_{B-\left\{b_{j}\right\}, S} \underline{a}(a, r)_{i t} x_{i t} .
$$

Therefore, buyer $b_{j}$ acquires object $s_{k}$ at the price

$$
p_{k}=V_{-j}(a, r)-\sum_{B-\left\{b_{j}\right\}, S} \underline{a}(a, r)_{i t} x_{i t}+r_{k}
$$

that is independent of any valuations of $b_{j}$. So, as in a Vickrey second-price auction for a single object, the price paid by a buyer with a quota of one is not determined by the valuation she states. Thus, she does not have an incentive to manipulate her valuation in the buyer-optimal competitive equilibrium rule.

\section{THE MANIPULABILITY THEOREMS}

In this section, we prove the two "folk theorems" stated in the introduction as corollaries of the General Manipulability Theorem. This theorem states that any agent who does not get her/his optimal equilibrium payoff in a market according to a competitive equilibrium rule can manipulate the rule. In these results, we analyze the agents' equilibrium behavior when the buyer-seller market has several competitive price vectors.

Theorem 5.1. (General Manipulability Theorem) Let $(\Pi, X)$ be any competitive equilibrium rule. Let $M \equiv M(a, r)$ be a market with more than one competitive price vector. Then any buyer (respectively, seller), whose vector of individual payoffs at $(\Pi(a, r) ; X(a, r))$ is different from her (respectively, his) vector of individual payoffs under the buyer-optimal (respectively, seller-optimal) competitive equilibrium for $M$ can manipulate $(\Pi, X)$ in $M$.

Proof. We write as lemmas some results that are proven in Sotomayor (1992), and Sotomayor (1999), respectively.

Lemma 5.1. If $(u, v ; x)$ is a competitive equilibrium outcome and $x$ ' is an optimal matching for $M$, then:

(i) $u_{j k}=\min _{k}\left\{u_{j k}\right\}$ for all $b_{j} \in B$ and $s_{k} \in C\left(b_{j}, x\right)-C\left(b_{j}, x^{\prime}\right)$.

(ii) There exists a competitive equilibrium outcome (u', v; $x$ ') such that $\min _{k}\left\{u_{j k}^{\prime}\right\}$

$=\min _{k}\left\{u_{j k}\right\}$ and $u_{j k}^{\prime}=u_{j k}$ for all $b_{j} \in B$ and $s_{k} \in C\left(b_{j}, x\right) \cap C\left(b_{j}, x^{\prime}\right)$.

(iii) ( $u, v ; x$ ') is also a competitive equilibrium outcome for $M$. 
Lemma 5.2. If $(u, v ; x)$ is a competitive equilibrium outcome for $M$, then $x$ is an optimal matching for $M$.

We now prove the theorem. The competitive equilibrium outcome if agents select the profile $(a, r)$ is $(u(a, r), \Pi(a, r)-r ; X(a, r))$. Let $(\bar{u}, \underline{p}-r)$ and $(\underline{u}, \bar{p}-r)$ be the buyer-optimal and the seller-optimal competitive equilibrium payoffs for $M$. Lemma 5.2 implies that $X(a, r)$ is optimal and Lemma 5.1 (iii) implies that it is compatible with $(\bar{u}, \underline{p}-r)$ and $(\underline{u}, \bar{p}-r)$. Furthermore, $\underline{p} \leq p \leq \bar{p}$, where $p$ is the equilibrium price vector of the competitive equilibrium outcome selected by the rule.

The case of a buyer: By hypothesis, $u(a, r) \neq \bar{u}$. Let $b_{j}$ be any buyer such that $u(a, r)_{j} \neq \bar{u}_{j}$. Then, there is some $s_{l} \in C\left(b_{j}, X(a, r)\right)$ such that $\bar{u}_{j l}>u(a, r)_{j l}$, which implies that the set $A_{j} \equiv\left\{s_{k} \in C\left(b_{j}, X(a, r)\right) ; \bar{u}_{j k}>u(a, r)_{j k}\right\}$ is non-empty. (Note that $\bar{u}_{j k}=u(a, r)_{j k}$ for all $\left.s_{k} \in C\left(b_{j}, X(a, r)\right)-A_{j}\right)$. Clearly, for all $s_{k} \in A_{j}, \bar{u}_{j k}>0$ and so $s_{k}$ $\neq s_{0}$. Furthermore, for every $s_{k} \in A_{j}$, there is some positive $\lambda_{k}$ such that $\bar{u}_{j k}>\bar{u}_{j k}-\lambda_{k}$ $>u(a, r)_{j k} \geq 0$, so $\bar{u}_{j k}-\lambda_{k}>0$.

Now define $a^{\prime}$ as follows: $a^{\prime}{ }_{i t}=a_{i t}$ for all $\left(b_{i}, s_{t}\right) \in B \times S$ with $b_{i} \neq b_{j} ; a^{\prime}{ }_{j k}=a_{j k}-$ $\left(\bar{u}_{j k}-\lambda_{k}\right)$ for all $s_{k} \in A_{j} ; a^{\prime}{ }_{j k}=a_{j k}-\bar{u}_{j k}$ for all $s_{k} \in C\left(b_{j}, X(a, r)\right)-A_{j}$; and $a^{\prime}{ }_{j k}=0$ for all $s_{k} \notin C\left(b_{j}, X(a, r)\right)$. It is a matter of verification that $a^{\prime}{ }_{i t} \geq 0$ for all $\left(b_{i}, s_{t}\right) \in B \mathrm{x} S$; hence, $a^{\prime}$ is well-defined. (It is enough to see that for all $s_{k} \in A_{j}, a^{\prime}{ }_{j k}=a_{j k}-\left(\bar{u}_{j k}-\lambda_{k}\right)$ $>a_{j k}-\bar{u}_{j k}=\underline{p}_{k} \geq 0$ and, for all $\left.s_{k} \in C\left(b_{j}, X(a, r)\right)-A_{j}, a^{\prime}{ }_{j k}=a_{j k}-\bar{u}_{j k}=\underline{p}_{k} \geq 0.\right)$

We show that $b_{j}$ 's total true payoff at allocation $\left(\Pi\left(a^{\prime}, r\right), X\left(a^{\prime}, r\right)\right)$ is strictly greater than at $(\Pi(a, r) ; X(a, r))$. First note that $\underline{p}$ is a competitive price vector for $M\left(a^{\prime}, r\right)$ because $b_{j}$ still demands the set $C\left(b_{j}, X(a, r)\right)$ at prices $\underline{p}$ in $M\left(a^{\prime}, r\right)$ and the demand sets of the other buyers do not change. Then, according to Lemma 5.1 (iii), $X(a, r)$ is compatible with every competitive price vector for $M\left(a^{\prime}, r\right)$; and by Lemma $5.2 X\left(a^{\prime}, r\right)$ is compatible with $\underline{p}$. Denote $B_{j} \equiv\left\{s_{k} ; s_{k} \in C\left(b_{j}, X(a, r)\right)-C\left(b_{j}, X\left(a^{\prime}, r\right)\right)\right\}$ and $B_{j}{ }_{j} \equiv\left\{s_{k} ; s_{k} \in C\left(b_{j}, X\left(a^{\prime}, r\right)\right)-C\left(b_{j}, X(a, r)\right)\right\}$. Clearly, $\left|B_{j}\right|=\left|B_{j}{ }_{j}\right|$. Also, denote $\bar{\mu}_{j}=\min \left\{\bar{u}_{j k} ; s_{k} \in C\left(b_{j}, X(a, r)\right)\right\}$. By Lemma 5.1 (i), since $(\bar{u}, \underline{p}-r)$ is compatible with $X(a, r)$ and $X\left(a^{\prime}, r\right)$, then $\bar{\mu}_{j}=a_{j q}-\underline{p}_{q}=a^{\prime}{ }_{j k}-\underline{p}_{k}$, for all $s_{q} \in B_{j}$ and $s_{k} \in B^{\prime}{ }_{j}$. By definition, $a^{\prime}{ }_{j k}=0$ for all $s_{k} \in B^{\prime}{ }_{j}$, so $\bar{\mu}_{j}=0$. Therefore, for all $s_{k} \in B^{\prime}{ }_{j}$ and $s_{q} \in B_{j}, \quad U_{j k}\left(\Pi\left(a^{\prime}, r\right), X\left(a^{\prime}, r\right) ; a, r\right)=a_{j k}-\Pi_{k}\left(a^{\prime}, r\right) \geq a_{j k}-a_{j k}^{\prime}=a_{j k} \geq 0=\bar{\mu}_{j}=\bar{u}_{j q} \geq$ $u(a, r)_{j q}$. We conclude that

$$
U_{j k}\left(\Pi\left(a^{\prime}, r\right), X\left(a^{\prime}, r\right) ; a, r\right) \geq u(a, r)_{j q}, \quad \forall s_{k} \in B^{\prime}{ }_{j} \text { and } s_{q} \in B_{j} .
$$

Equation (3) states that $b_{j}$ 's utility derived from any new transactions (those under $X\left(a^{\prime}, r\right)$ and not under $\left.X(a, r)\right)$ is larger than the utility derived from any transactions that do not take place in the new situation. 
Now observe that, at every equilibrium price $p^{\prime}$ for $M\left(a^{\prime}, r\right)$, and for all $s_{k} \in A_{j}$ and $s_{q} \notin C\left(b_{j}, X(a, r)\right)$, we have $a^{\prime}{ }_{j k}-p^{\prime}{ }_{k}=\left(\underline{p}_{k}-p^{\prime}{ }_{k}\right)+\lambda_{k}>0 \geq-p^{\prime}{ }_{q}=a_{j q}{ }_{j q}-p^{\prime}{ }_{q}$, so $a_{j k}^{\prime}-p^{\prime}{ }_{k}>a_{j q}^{\prime}-p^{\prime}{ }_{q}$. This implies that every $s_{k} \in A_{j}$ is matched to $b_{j}$ at any optimal matching for $M\left(a^{\prime}, r\right)$, and in particular at $X\left(a^{\prime}, r\right)$, from which it follows that $A_{j} \subseteq C\left(b_{j}, X(a, r)\right) \cap C\left(b_{j}, X\left(a^{\prime}, r\right)\right)$. Moreover, for all $s_{k} \in A_{j}$ we have that $U_{j k}\left(\Pi\left(a^{\prime}, r\right), X\left(a^{\prime}, r\right) ; a, r\right)=a_{j k}-\Pi_{k}\left(a^{\prime}, r\right) \geq a_{j k}-a^{\prime}{ }_{j k}=\bar{u}_{j k}-\lambda_{k}>u(a, r)_{j k}$. Thus,

$$
U_{j k}\left(\Pi\left(a^{\prime}, r\right), X\left(a^{\prime}, r\right) ; a, r\right)>u(a, r)_{j k}, \forall s_{k} \in A_{j} \subseteq C\left(b_{j}, X(a, r)\right) \cap C\left(b_{j}, X\left(a^{\prime}, r\right)\right)_{j}
$$

Finally, for all $s_{k} \in C\left(b_{j}, X(a, r)\right) \cap C\left(b_{j}, X(a, r)\right)-A_{j}$ the following holds: $U_{j k}\left(\Pi\left(a^{\prime}, r\right), X\left(a^{\prime}, r\right) ; a, r\right)=a_{j k}-\Pi_{k}\left(a^{\prime}, r\right) \geq a_{j k}-a^{\prime}{ }_{j k}=\bar{u}_{j k}=u(a, r)_{j k}$. Therefore,

$$
U_{j k}\left(\Pi\left(a^{\prime}, r\right), X\left(a^{\prime}, r\right) ; a, r\right) \geq u(a, r)_{j k}, \forall s_{k} \in C\left(b_{j}, X\left(a^{\prime}, r\right)\right) \cap C\left(b_{j}, X\left(a^{\prime}, r\right)\right)-A_{j} .
$$

The result follows from (3), (4), (5), $|B|=\left|B^{\prime}\right|$, and $A_{j} \neq \varnothing$ (if $|B|=0$, the result also holds following (4) and (5)). Hence, the proof of this case is complete.

The case of a seller: By hypothesis, $\Pi(a, r) \neq \bar{p}$. Let $s_{k}$ be any seller for whom $\bar{p}_{k}>\Pi_{k}(a, r) \geq r_{k}$. Then $\bar{p}_{k}>r_{k}$, so seller $s_{k}$ sells all his objects at $X(a, r)$. Furthermore, for some positive $\lambda, \bar{p}_{k}>\bar{p}_{k}-\lambda>\Pi_{k}(a, r)$.

Let $r^{\prime}$ be defined as follows: $r_{t}^{\prime}=r_{t}$ for all $s_{t} \neq s_{k}$ and $r^{\prime}{ }_{k}=\bar{p}_{k}-\lambda$. That is, under the profile $\left(a, r^{\prime}\right), s_{k}$ replaces his true valuation by $r^{\prime}{ }_{k}$, whereas the other players keep their valuations.

First note that $\bar{p}_{t} \geq r^{\prime}$, for all $s_{t}$, which implies that $(\bar{p}, X(a, r))$ is a feasible allocation for $M\left(a, r^{\prime}\right)$. Now use the fact that $(\bar{p}, X(a, r))$ is a competitive equilibrium in $M(a, r)$ and that if $s_{t}$ does not sell some objects at $X(a, r)$, then $s_{t} \neq s_{k}$, so $\bar{p}_{t}=r_{t}=r^{\prime}$, to obtain that $(\bar{p}, X(a, r))$ is a competitive equilibrium for $M\left(a, r^{\prime}\right)$. As $\bar{p}_{k}-r^{\prime}{ }_{k}=\lambda>0$, it follows that $s_{k}$ sells all his objects at any optimal matching for $M\left(a, r^{\prime}\right)$; in particular, $s_{k}$ sells all his objects at $X\left(a, r^{\prime}\right)$. Hence, the seller's individual payoff from each object is

$$
V_{k}\left(\Pi\left(a, r^{\prime}\right), X\left(a, r^{\prime}\right)\right)=\Pi_{k}\left(a, r^{\prime}\right)-r_{k} \geq r^{\prime}{ }_{k}-r_{k}=\left(\bar{p}_{k}-\lambda-r_{k}\right)>\Pi_{k}(a, r)-r_{k} .
$$

Theorem 5.1 implies, in particular, that for any competitive equilibrium rule $(\Pi, X)$ (not necessarily one of the optimal rules), if $(\Pi(a, r), X(a, r))$ is not the buyer(respectively, seller-) optimal competitive equilibrium for market $M(a, r)$, then in the induced game $\Gamma(\Pi, X, a, r)$, truthful behavior is not a best response for at least one buyer (respectively, seller). In particular,

Corollary 5.1. (Manipulability Theorem) Consider the buyer-optimal (respectively, seller-optimal) competitive equilibrium rule. Suppose that $M(a, r)$ has more than one 
vector of equilibrium prices. Then there is a seller (respectively, buyer) who can manipulate the rule via $M(a, r)$.

Another immediate consequence of Theorem 5.1 is that for every market with more than one vector of competitive equilibrium prices, there is no competitive equilibrium rule such that the induced game gives every agent an incentive to play her/his sincere strategy. For the proof of the old impossibility result, Roth and Sotomayor (1990) constructed an example with one seller and $n>1$ buyers and showed that any competitive equilibrium rule can be manipulated by either the seller or one of the buyers. Corollary 5.2 strengthens this result by stating that every competitive equilibrium rule is manipulable in every market that has more than one vector of equilibrium prices.

Corollary 5.2. (General Impossibility Theorem) Suppose that the market $M$ has more than one vector of equilibrium prices. Then every competitive equilibrium rule is manipulable in $M$.

Corollaries 5.1 and 5.2 are valid under the assumption that the market has more than one vector of equilibrium price vectors. Sotomayor (2002) proved that this assumption holds in the one-to-one assignment game when there is only one optimal matching, which is generically the case. Furthermore, for any buyer-seller market, Sotomayor (1992) constructed a related assignment game via an appropriate definition of the matrix of valuations and she showed that there is a one-to-one correspondence between the set of competitive equilibrium allocations for the two models. This implies that, also for the buyer-seller market, there are always more than one competitive equililibrium price vectors, except in the ulikely situation where the market has several optimal matchings. Thefore, Corollaries 5.1 and 5.2 apply very generally. ${ }^{16}$

We now use the manipulability and non-manipulability theorems to state the necessary and sufficient conditions for an agent with a quota of one to be able to manipulate a competitive equilibrium rule.

\footnotetext{
${ }^{16}$ Consider a market with more than one optimal matching and only one competitive equilibrium price. Then, add any small $\varepsilon>0$ to the valuation of any of the buyers who is matched under an optimal matching $x$. The maching $x$ becomes the only optimal matching and, hence, the new market has more than one competitive equilibrium price.
} 
Theorem 5.2. Let $M=M(a, r)$ be a market and (I, $X)$ a competitive equilibrium rule. Consider a buyer (respectively, seller) with a quota of one. Then, this agent cannot manipulate $(\Pi, X)$ in $M$ if and only if $(\Pi(a, r), X(a, r))$ gives to the agent her (respectively, his) most preferred equilibrium payoff in $M$.

Proof. The first direction is immediate after Theorem 5.1. The other direction follows from Theorem 4.1, if the agent is a seller or Theorem 4.3, if the agent is a buyer.

In particular, for the assignment game we can state the following corollary, which follows immediately after Theorem 5.2.

Corollary 5.3. Suppose all agents have a quota of one. Let $M=M(a, r)$ be a market and (П, X) a competitive equilibrium rule. Then, no buyer (respectively, seller) can manipulate $(\Pi, X)$ in $M$ if and only if $(\Pi(a, r), X(a, r))$ is the buyer-optimal (respectively, seller-optimal) competitive equilibrium rule.

Corollary 5.3 implies that when all agents have a quota of one, no agent can manipulate $(\Pi, X)$ in $M(a, r)$ if and only if $M(a, r)$ has only one equilibrium price vector. This is an interesting result that does not extend to one-to-many or many-to-one buyer-seller markets. For instance, if the number of identical objects owned by a seller is larger than the number of buyers, then the only equilibrium price of these objects is equal to the seller's valuation. However, he often has an incentive to claim a higher valuation and obtain profits from a buyer whose valuation is higher that the seller's true valuation. And similar examples can be constructed if a buyer is interested in acquiring more than one object.

Finally, we state the necessary and sufficient condition for a competitive equilibrium rule to be strategy-proof for one side of the market in the assignment game.

Corollary 5.4. Suppose all agents have a quota of one. The competitive equilibrium rule $(\Pi, X)$ is strategy proof by the buyers (respectively, sellers) if and only if $(\Pi, X)$ is the buyer-optimal (respectively, seller-optimal) competitive equilibrium rule.

\section{CONCLUSION AND EXTENSIONS}

We have analyzed sellers' and buyers' incentives if competitive equilibrium rules are applied. First, we have shown that although the Non-Manipulability Theorem for the 
one-to-one buyer-seller market cannot be generalized for the many-to-many buyer-seller market, it can be extended to the model where all agents of one of the sides of the market have a quota of one. Second, we have proven a General Manipulability Theorem for the many-to-many buyer-seller market. The theorem states that if a competitive equilibrium rule does not yield the buyer- (seller-) optimal competitive equilibrium for an instance of the buyer-seller market, then any buyer (seller) who does not receive his (her) optimal equilibrium payoff has an incentive to misrepresent his (her) preferences. This theorem has two corollaries which are extensions of two important "folk theorems" for Shapley and Shubik's (1972) one-to-one assignment game. Moreover, restricted to the assignment game, it is a sort of converse of the Non-Manipulability Theorem.

We have studied a market that is more general than the classic assignment game. Therefore, in addition to the questions that we have addressed, our analysis opens the door to other interesting problems that are outside the scope of the current paper and left for future research. We briefly discuss some of the open questions.

First, given that each agent has a quota larger than one in our market, a natural question is whether agents can manipulate the competitive rules with respect to the quotas, if the quotas are not public information. While we do not have general results, our intuition is that manipulating the quotas is often profitable for the agents. To support this intuition, we provide here examples where a buyer can manipulate through the quota the maximum or the minimum competitive equilibrium rule. Consider first the minimum competitive equilibrium rule. Take the market with $B=\left\{b_{1}, b_{2}\right\}, S=\left\{s_{1}, s_{2}\right\}$, the buyers' valuations are $a_{11}=3, a_{12}=2, a_{21}=a_{22}=3$, the sellers' valuations are zero, the quota of $b_{1}$ is 2 , and the quota of the rest of agents is 1 . If all agents report their true valuations and quotas, the price of each object is 2 . Buyer $b_{1}$ gets only the object of seller $s_{1}$ and obtains a total utility of 1 (buyer $b_{2}$ gets the object of seller $s_{2}$ ). However, if buyer $b_{1}$ misrepresents her quota and reports that it is 1 , then she receives the same object as before but at the price of 0 . That is, she is strictly better off by decreasing her quota. Consider now the maximum competitive equilibrium rule and a market where there is only one buyer with a quota of 2 , and two sellers with an object each and a reservation value of zero. The buyer's valuations are $a_{11}=3$ and $a_{12}=2$. The maximum competitive equilibrium prices for the objects are 3 and 2 and the buyer gets a zero payoff. However, the buyer has an incentive to report a quota of 1 , since she would get a payoff of 2 in the new market by buying the first object at a price of 1 . 
Second, we have studied a market where the value of an object for a buyer does not depend on the other objects that she acquires or on the other buyers acquiring a similar object. This condition implies, in particular, that the preferences of the buyers fulfill the "gross substitutes condition." As Kelso and Crawford (1982) emphasized, competitive equilibria often do not exist when objects can be complementary from the buyers' point of view. The analysis of competitive equilibria and the manipulability of competitive equilibrium rules in markets where buyers have more general preferences are interesting and very challenging problems.

Finally, we have assumed that each buyer can only obtain one object of the same seller. The model in which a buyer can obtain more than one object of the same seller is treated in Sotomayor (2008) and Jaume, Massó, and Neme (2012). ${ }^{17}$ In this situation, it is easy to construct an example where buyers cannot manipulate the minimum competitive equilibrium but they can manipulate the maximum competitive equilibrium. Consider only one buyer with a quota of 5 and two sellers, $s_{1}$ with a quota of 4 and $s_{2}$ with a quota of 1 . The buyer valuations are $a_{11}=a_{12}=3$. In this market, the price of each object is 3 at the maximum competitive equilibrium. Clearly, the buyer has an incentive to manipulate her valuations by reporting $a_{11}^{\prime}=a_{12}^{\prime}=0$. However, general theorems about the manipulability of the rules in these markets cannot be proved with the theory developed in the present paper.

\section{REFERENCES}

Andersson T, Ehlers L, Svensson LG (2014) Budget balance, fairness, and minimal manipulability. Theor Econ 9: 753-777.

Andersson T, Svensson LG (2008) Non-manipulable assignment of individuals to positions revisited. Math Soc Sci 56: 350-354.

Ausubel L (2004) An efficient ascending-bid auction for multiple objects. Am Econ Rev 94: 1452-1475.

Ausubel L (2006) An efficient dynamic auction for heterogeneous commodities. Am Econ Rev 96: 602-629.

Barberà S, Berga D, Moreno B (2016) Group strategy-proofness in private good economies. Am Econ Rev 106: 1073-1099.

\footnotetext{
${ }^{17}$ Sotomayor (2008) also considers the case where the quotas of the agents are not integer numbers. In this case, the quotas can be interpreted as the amount of time available to each agent, which can be distributed among the partnerships the agent forms.
} 
Crawford VP, Knoer EM (1981) Job matching with heterogeneous firms and workers. Econometrica 49: 437-450.

Demange G (1982) Strategyproofness in the assignment market game. Preprint. Paris: École Polytechnique, Laboratoire d'Économetrie.

Demange G, Gale D (1985) The strategy structure of two-sided matching markets. Econometrica 55: 873-88.

Demange G, Gale D, Sotomayor M (1986) Multi-item auctions. J Polit Econ 94: 86372.

Fujinaka Y, Wakayama T (2015) Maximal manipulation of envy-free solutions in economies with indivisible goods and money. J Econ Theory 158: 165-185.

Gale D (1960) The theory of linear economic models. New York, McGraw Hill.

Gul F, Stacchetti E (2000) The English auction with differential commodities. J Econ Theory 92: 66-95.

Hatfield JW, Milgrom PR (2005) Matching with contracts. Am Econ Rev 95: 913-935. Jaramillo P, Kayi C, Klijn F (2013) Equilibria under deferred acceptance: Dropping strategies, filled positions, and welfare. Game Econ Behav 82: 693-701.

Jaume D, Massó J, Neme A (2012) The multiple-partners assignment game with heterogeneous sales and multi-unit demands: competitive equilibria. Math Meth Oper Res 76: 161-187.

Kelso A, Crawford VP (1982) Job matching, coalition formation, and gross substitutes. Econometrica 50: 1483-1504.

Kojima F, Pathak PA (2009) Incentives and stability in large two-sided matching markets," Am Econ Rev 99: 608-627.

Leonard HB (1983) Elicitation of honest preferences for the assignment of individuals to positions. J Polit Econ 91. 461-479.

Ma J (2010) The singleton core in the hospital-admissions problem and its application to the National Resident Matching Program (NRMP). Game Econ Behav 69:150-164.

Miyake M (1998) On the incentive properties of multi-item auctions. Int J Game Theory 27: 1-19.

Roth A (1985) The college admissions problem is not equivalent to the marriage problem. J Econ Theory 36: 277-288.

Roth A, Sotomayor M (1990) Two-sided matching. A study in game-theoretic modeling and analysis. Econometric Society Monograph Series, N. 18 Cambridge U Press.

Sakai T (2011) A note on strategy-proofness from the doctor side in matching with contracts. Rev Econ Design 15: 337-342. 
Shapley L, Shubik M (1972) The assignment game I: The core. Int J Game Theory 1: 111-130.

Sotomayor M (1992) The multiple partners game. In Majumdar M (ed) Equilibrium and dynamics. The MacMillan Press LTD, London.

Sotomayor M (1999) The lattice structure of the set of stable outcomes of the multiple partners assignment game. Int J Game Theory 28: 567-583.

Sotomayor M (2000) Buying and selling mechanisms with random matching rules yielding pricing competition. WP.

Sotomayor M (2007) Connecting the cooperative and competitive structures of the multiple-partners assignment game. J Econ Theory 134: 155-74.

Sotomayor M (2008) Labor time shared in the assignment game lending new insights to the theory of two-sided matching markets. First version, 2008; pre-print in FEA/USP WPA 2012-29.

Sotomayor M (2012) A further note on the college admission game. Int J Game Theory 41: 179-193.

Sun N, Yang Z (2003) A general strategy proof fair allocation mechanism. Econ Lett 81: 73-79.

Sun N, Yang Z (2014) An efficient and incentive compatible dynamic auction for multiple complements. J Polit Econ 122: 422-466.

Svensson LG (2009) Coalitional strategy-proofness and fairness. Econ Theory 40: 227245.

\section{APPENDIX}

Proof of Lemma 4.2. (i) Suppose that $\left(u^{\prime}, v^{\prime} ; x^{\prime}\right)$ is feasible for $M(\underline{a})$. If $x^{\prime} \#_{j(q) k(h)}=1$ then $x_{j k}^{\prime}=1$ and $\underline{a}_{j(q) k(h)}=\underline{a}_{j k}$ by the Key Lemma. Then, $u^{\prime} \#_{j(q)}+v^{\prime} \#_{k(h)}=u_{j k}^{\prime}+v_{j k}^{\prime}=$ $\underline{a}_{j k}=\underline{a}_{j(q) k(h)}$. By definition, $u^{\prime} \#_{j(q)} \geq 0$ and $v^{\prime} \#_{k(h)} \geq 0$. Hence, $\left(u u^{\prime}, v^{\prime} \# ; x^{\prime} \#\right)$ is a pairwise-feasible outcome for $M(\underline{a} \#)$, so it is feasible for $M(\underline{a} \#)$.

In the other direction, suppose that $\left(u^{\prime} \#, v^{\prime} \# ; x^{\prime} \#\right)$ is feasible for $M(\underline{a} \#)$. If $x_{j k}^{\prime}=1$, then $x^{\prime} \#_{j(q) k(h)}=1$ for some pair $\left(b_{j(q)}, s_{k(h)}\right) \in B \# \mathrm{x} S \#$ by the Key Lemma and $\underline{a}_{j(q) k(h)}$ $=\underline{a}_{j k}$ by the definition of $\underline{a} \#$. Then $u_{j k}^{\prime}+v_{j k}^{\prime}=u^{\prime} \#_{j(q)}+v^{\prime} \#_{k(h)}=\underline{a}_{j(q) k(h)}=\underline{a}_{j k}$. By definition, $u_{j k}^{\prime} \geq 0$ and $v_{j k}^{\prime} \geq 0$. Hence, $\left(u^{\prime}, v^{\prime} ; x^{\prime}\right)$ is a pairwise-feasible outcome for $M(\underline{a})$, so it is feasible for $M(\underline{a})$. 
(ii) Suppose that $\left(u^{\prime}, v^{\prime} ; x^{\prime}\right)$ is a competitive equilibrium for $M(\underline{a})$. Then, $x^{\prime} \#$ is an optimal matching for $M(\underline{a} \#)$. Also, $\left(u^{\prime}, v^{\prime} ; x\right)$ is a competitive equilibrium for $M(\underline{a})$ (see Theorem 1 of Sotomayor, 1999). Moreover, if $x \#_{j(q) k(h)}=0$, we have either (1) $x_{j k}=$ 0 , in which case $\min _{k}\left\{u_{j k}^{\prime}\right\}+\min _{j}\left\{v_{j k}^{\prime}\right\} \geq \underline{a}_{j k}$ by Proposition 2.1, which implies $u^{\prime} \#_{j(q)}$ $+v^{\prime} \#_{k(h)} \geq \min _{k}\left\{u_{j k}^{\prime}\right\}+\min _{j}\left\{v_{j k}^{\prime}\right\} \geq \underline{a}_{j k}=\underline{a}_{j(q) k(h)}$, where the last equality follows from the definition of $\underline{a} \#$; or (2) $x_{j k}=1$, in which case $u^{\prime} \#_{j(q)}+v^{\prime} \#_{k(h)} \geq 0=\underline{a} \#_{j(q) k(h)}$. In either case, we obtain that $\left(u^{\prime} \#, v^{\prime} \# ; x \#\right)$ is a competitive equilibrium for $M(\underline{a} \#)$. Then, by the optimality of $x^{\prime} \#,\left(u^{\prime} \#, v^{\prime} \# ; x^{\prime} \#\right)$ is also a competitive equilibrium for $M(\underline{a} \#)$.

(iii) Suppose that $\left(u^{\prime} \#, v^{\prime} \# ; x^{\prime} \#\right)$ is a competitive equilibrium for $M(\underline{a} \#)$. Then $\left(u^{\prime} \#, v^{\prime} \# ; x \#\right)$ is also a competitive equilibrium for $M(\underline{a} \#)$. Moreover, $x$ '\# is an optimal matching for $M(\underline{a} \#)$, which implies that $x^{\prime}$ is an optimal matching for $M(\underline{a})$. Then, if $x_{j k}=0$ we have that $x \#_{j(q) k(h)}=0$ and $\underline{a}_{j(q) k(h)}=\underline{a}_{j k}$ for all $b_{j(q)} \in B \#$ and all $s_{k(h)} \in S \#$. The definition of $\left(u^{\prime} \#, v^{\prime} \#\right)$ implies that $\min _{k}\left\{u_{j k}^{\prime}\right\}=u^{\prime} \#_{j(q)}$ for some $b_{j(q)} \in B \#$ and $\min _{j}\left\{v_{j k}^{\prime}\right\}=v^{\prime} \#_{k(h)}$ for some $s_{k(h)} \in S \#$. Hence, $\min _{k}\left\{u_{j k}^{\prime}\right\}+\min _{j}\left\{v_{j k}^{\prime}\right\}=u^{\prime} \#_{j(q)}+v^{\prime} \#_{k(h)}$ $\geq \underline{a}_{j(q) k(h)}=\underline{a}_{j k}$. By hypothesis, $v_{i k}^{\prime}=\min _{j}\left\{v_{j k}^{\prime}\right\}$ holds for all $b_{i} \in C\left(s_{k}, x\right)$. Then, Proposition 2.1 implies that $\left(u^{\prime}, v^{\prime} ; x\right)$ is a competitive equilibrium outcome for $M(\underline{a})$. Since $x^{\prime}$ is optimal for $M(\underline{a})$, Theorem 1 of Sotomayor (1999) implies that ( $\left.u^{\prime}, v^{\prime} ; x^{\prime}\right)$ is a competitive equilibrium outcome for $M(\underline{a})$.

Proof of Lemma 4.3. Define the outcome $\left(u^{\prime}, v^{\prime} ; x \#\right)$ for $M(\underline{a} \#)$ as follows: $v_{k(z)}^{\prime} \equiv$ $\min \left\{v_{k(1)}, \ldots, v_{k(t(s k))}\right\}$ for all $s_{k(z)} \in S \#$ and the payoff vector $u$ ' is defined pairwisefeasibly. We claim that $\left(u^{\prime}, v^{\prime} ; x \#\right)$ is a competitive equilibrium outcome for $M(\underline{a} \#)$. First, it is clear that $\left(u^{\prime}, v^{\prime} ; x \#\right)$ is feasible for $M(\underline{a} \#)$ by definition. Second, $u_{j(q)}^{\prime} \geq$ $u_{j(q)}$ for all $b_{j(q)} \in B \#$ because $v_{k(z)}^{\prime} \leq v_{k(z)}$ for all $s_{k(z)} \in S \#$. Consider now a pair $\left(b_{j(q)}, s_{k(h)}\right)$ with $x \#_{j(q) k(h)}=0$ and let $l \leq t\left(s_{k}\right)$ such that $v_{k(l)}=\min \left\{v_{k(1)}, \ldots, v_{k(t(s k))}\right\}$. There are two cases.

Case 1. $x_{j k}=0$, in which case $\underline{a}_{j(q) k(h)}=\underline{a}_{j(q) k(l)}$. It follows that $u_{j(q)}^{\prime}+v_{k(h)}^{\prime} \geq u_{j(q)}+v_{k(l)}$ $\geq \underline{a}_{j(q) k(l)}=\underline{a}_{j(q) k(h)}$, where we use Proposition 2.1 in the last inequality.

Case 2. $x_{j k}=1$, in which case $\underline{a}_{j(q) k(h)}=0$. It follows that $u_{j(q)}^{\prime}+v_{k(h)}^{\prime} \geq u_{j(q)}+v_{k(l)} \geq 0=$ $\underline{a}_{j(q) k(h)}$.

Given that $u_{j(q)}^{\prime}+v_{k(h)}^{\prime} \geq \underline{a}_{j(q) k(h)}$ for all $\left(b_{j(q)}, s_{k(h)}\right)$ with $x \#_{j(q) k(h)}=0$, the result that $\left(u^{\prime}, v^{\prime} ; x \#\right)$ is a competitive equilibrium outcome for $M(\underline{a} \#)$ follows from Proposition 2.1 .

We now use Lemma 4.2 to obtain that the outcome ( $u$ ", $v$ ”; $x$ ) related to $\left(u^{\prime}, v^{\prime} ; x \#\right)$ is competitive for $M(\underline{a})$. Then, by the optimality for $S$ of $(\underline{u}, \bar{v})$ in $M(\underline{a})$, 
$v_{k}{ }^{\prime} \leq \bar{v}_{k}$ for all $s_{k}$ with a quota of one.

On the other hand, let $\left(\underline{u}, \bar{v}^{\prime} ; x \#\right)$ be the competitive equilibrium outcome related to $(\underline{u}, \bar{v} ; x)$ according to Lemma 4.2. By the optimality for $S \#$ of $(u, v ; x \#)$ in $M(\underline{a} \#)$ we have that $\bar{v}_{k(h)} \leq v_{k(h)}$ for all $s_{k(h)} \in S \#$. We also have that $v_{k}=v^{\prime}{ }_{k}$ for all $s_{k}$ with $t\left(s_{k}\right)=1$. Therefore, if $t\left(s_{k}\right)=1$ we must have that

$$
\bar{v}_{k}=\bar{v}^{\prime}{ }_{k} \leq v_{k}=v^{\prime}{ }_{k}=v^{\prime}{ }_{k} \text {. }
$$

From (A1) and (A2) we obtain that $\bar{v}_{k}=v^{\prime \prime}{ }_{k}$ so the inequality in (A2) is in fact an equality and so $\bar{v}_{k}=v_{k}$ for all $s_{k}$ with a quota of one, which concludes the proof.

Proof of Lemma 4.4. If $B+\neq \varnothing$, Lemma 9.20 of Roth and Sotomayor (1990), due to Demange and Gale (1985), implies that there exist $b_{j(q)} \in B \#-B+$ and $s_{k(h)} \in x(B+)$ such that $\left(b_{j(q)}, s_{k(h)}\right)$ blocks $(u, v ; x)$. Since $b_{j(q)} \in B \#-B+, u_{j(q)} \leq u_{j(q)}^{+}$. Also, since $s_{k(h)} \in$ $x(B+)$ there exists some $b_{l(m)} \in B+$ such that $x_{l(m) k(h)}=1$. Then, $u_{l(m)}>u_{l(m)}^{+}$so $v_{k(h)} \leq$ $\mathrm{v}_{k(h)}^{-} \leq v_{k(h)}^{+}$by the competitiveness of $\left(u^{+}, v^{-}\right)$. Therefore, $s_{k(h)} \notin S+$.

Proof of Lemma 4.6. (i) Suppose by contradiction that $x\left(S-S^{\prime}\right)=\left\{b_{0}\right\}$. Given that $s_{0} \in S-S^{\prime}, x\left(S-S^{\prime}\right)=\left\{b_{0}\right\}$ implies that if $s_{k} \in S^{\prime}$ and $x_{j k}=1$, then $b_{j} \neq b_{0}$. Moreover, every $b_{j} \neq b_{0}$ fills her quota and does that with sellers in $S^{\prime}$. That is, $x\left(S^{\prime}\right)=B-\left\{b_{0}\right\}$. Then take $\lambda>0$ such that $\underline{v}_{k}-\lambda>0$ for all $s_{k} \in S^{\prime}$ and define $(u, v ; x)$ as follows:

$$
\begin{aligned}
& v_{k}=\underline{v}_{k}-\lambda \text { if } s_{k} \in S^{\prime} \text { and } v_{k}=\underline{v}_{k}, \text { otherwise; } \\
& u_{j k}=\bar{u}_{j k}+\lambda \text { if } b_{j} \in x\left(S^{\prime}\right)=B-\left\{b_{0}\right\} \text { and } x_{j k}=1 ; \\
& u_{0 k}=\bar{u}_{0 k}=0 \text { if } x_{0 k}=1 .
\end{aligned}
$$

We claim that $(u, v ; x)$ is a competitive equilibrium outcome for $M(a, r)$. In fact, the feasibility of $(u, v ; x)$ and condition (iii) of Proposition 2.1 are clearly satisfied. To show that $\min _{k}\left\{u_{j k}\right\}+v_{k} \geq a_{j k}-r_{k}$ for all $\left(b_{j}, s_{k}\right) \in B \mathrm{x} S$, use the construction of $(u, v ; x)$ and the fact that $(\bar{u}, \underline{v} ; x)$ is a competitive equilibrium outcome for the case when $b_{j} \neq b_{0}$. When $b_{j}=b_{0}$, it is enough to verify the inequality when $s_{k} \in S^{\prime}$. In this case, we have that $\min _{k}\left\{u_{j k}\right\}+v_{k}=\underline{v}_{k}-\lambda>0=a_{0 k}-r_{k}=a_{j k}-r_{k}$. However, $v_{k}<\underline{v}_{k}$ for all $s_{k} \in S^{\prime}$, and $S^{\prime} \neq \varnothing$, which contradicts the fact that $(\bar{u}, \underline{v} ; x)$ is a seller-optimal competitive equilibrium outcome for $M(a, r)$. Hence, $x\left(S-S^{\prime}\right) \neq b_{0}$.

(ii) Arguing by contradiction, suppose $\bar{u}_{j t}+\underline{v}_{k}>a_{j k}-r_{k}$ for all $\left(b_{j}, s_{k}\right) \in x\left(S-S^{\prime}\right) \mathrm{x} S^{\prime}$ with $b_{j} \neq b_{0}$ and $x_{j k}=0$, and for all $s_{t} \in S-S^{\prime}$ with $x_{j t}=1$. Then there exists $\lambda>0$ such that $\underline{v}_{k}-\lambda>0$ for all $s_{k} \in S^{\prime}$ and also such that for all $\left(b_{j}, s_{k}\right) \in x\left(S-S^{\prime}\right) \mathrm{x} S^{\prime}$, with $b_{j} \neq b_{0}$ and $x_{j k}=0$, and for all $s_{t} \in S-S^{\prime}$ with $x_{j t}=1$, the parameter $\lambda$ satisfies

$$
\bar{u}_{j t}+\underline{v}_{k}-\lambda>a_{j k}-r_{k} \text {. }
$$


Now, define $\left(u^{\prime}, v^{\prime} ; x\right)$ as follows:

$$
\begin{aligned}
& v^{\prime}{ }_{k}=\underline{v}_{k}-\lambda \text { if } s_{k} \in S^{\prime} \text { and } v^{\prime}{ }_{k}=\underline{v}_{k}, \text { otherwise; } \\
& u^{\prime}{ }_{j k}=\bar{u}_{j k}+\lambda \text { if } s_{k} \in S^{\prime} \text { and } x_{j k}=1 \\
& u^{\prime}{ }_{j k}=\bar{u}_{\mathrm{j} k} \text { if } s_{k} \in S-S^{\prime} \text { and } x_{j k}=1
\end{aligned}
$$

We claim that $\left(u^{\prime}, v^{\prime} ; x\right)$ is a competitive equilibrium outcome. The argument is similar to the one used in part (i). We only need to check that $\min _{k}\left\{u_{j k}^{\prime}\right\}+v^{\prime}{ }_{k} \geq a_{j k}-r_{k}$ for all $s_{k} \in S^{\prime}$ and $x_{j k}=0$. Then, let $\left(b_{j}, s_{k}\right) \in B \times S$, with $x_{j k}=0$ and let $\min _{k}\left\{u^{\prime}{ }_{j k}\right\}=u^{\prime}{ }_{j t}$, for some $s_{t} \in C\left(b_{j}, x\right)$. If $s_{t} \in S^{\prime}$ then the result follows from the competitiveness of $(\bar{u}, \underline{v} ; x)$; if $s_{t} \in S-S^{\prime}$ the result follows from (A1).

However, $v^{\prime}{ }_{k}<\underline{v}_{k}$ for all $s_{k} \in S^{\prime}$, and $S^{\prime} \neq \varnothing$, which contradicts that $(\bar{u}, \underline{v} ; x)$ is buyer-optimal for $M(a, r)$. 